\title{
Idaho National Laboratory Annual Report FY 2012 LDRD Snapshot
}

March 2013

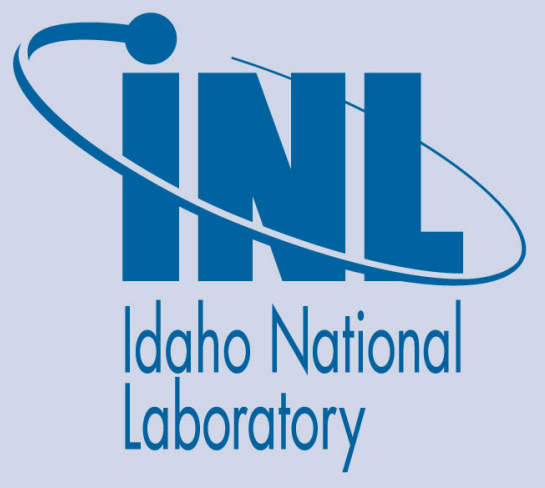

The INL is a U.S. Department of Energy National Laboratory operated by Battelle Energy Alliance 
INL/EXT-13-28582

\title{
Idaho National Laboratory Annual Report FY 2012 LDRD Snapshot
}

March 2013

\author{
Idaho National Laboratory \\ Idaho Falls, Idaho 83415
}

http://www.inl.gov

Prepared for the

U.S. Department of Energy

Through the INL LDRD Program

Under DOE Idaho Operations Office

Contract DE-AC07-05ID14517 
Idaho National Laboratory ANNUAL REPORT FY2012

\section{LDRD SNAPSHOT}

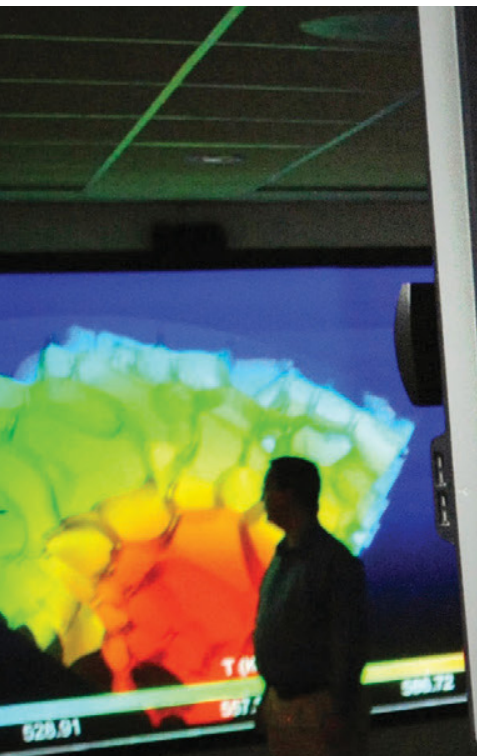

क्ये 


\section{FROM THE DIRECTOR}

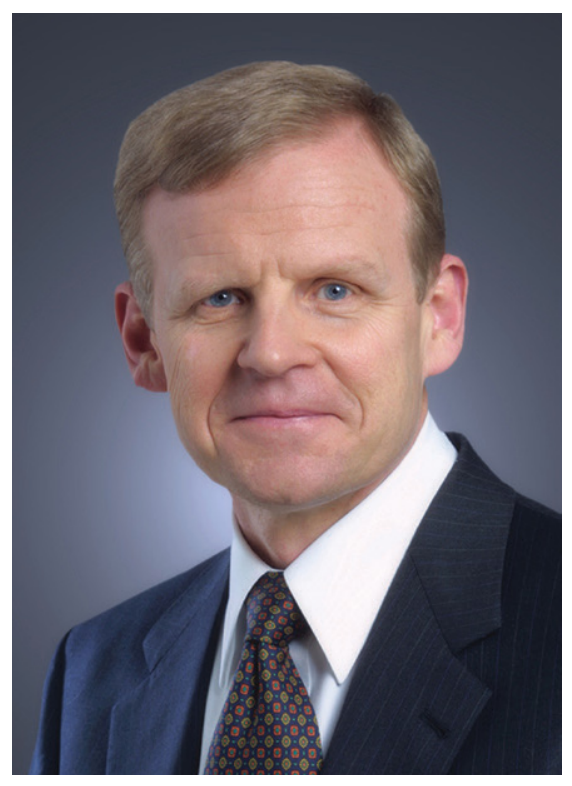

John Grossenbacher

Director, Idaho National Laboratory

\section{March 2013}

It is my pleasure to present the Idaho National Laboratory (INL) Fiscal Year 2012 Laboratory Directed Research and Development (LDRD) Annual Report. This report demonstrates the types of cutting-edge research INL is undertaking to mature our technical capabilities and help ensure the nation's energy security. This year we've added a new element, the LDRD Snapshot, to highlight the program's research diversity, university collaborations, metrics and successes.

INL's LDRD program is operated in compliance with the Department of Energy (DOE) order 413.2B. This work aligns with INL's strategic plan and benefits the DOE. The program's diverse research and development emphasizes the DOE Office of Nuclear Energy (DOE-NE) mission, which encompasses both advanced nuclear science and technology, and underlying technologies. INL's LDRD program also advances that mission by helping develop technical capabilities necessary to support future DOE-NE research and development needs. Research areas during FY 2012 included control room modernization, nuclear material fabrication, advanced reactor modeling, next-generation test reactor research, stronger nuclear materials, fuel modeling, waste reduction, fuel recycling, and advanced radiation detection

As a multiprogram national laboratory, INL research serves the nation through technology that enhances homeland security. These research areas include wireless technologies, cybersecurity, electric grid reliability, nuclear nonproliferation and explosives protection. INL's isolated site and test bed infrastructure are ideal for experimentation and demonstrations that help protect the nation's resources and advance energy security.

INL's science base is further strengthened by research to advance alternative energy systems that reduce greenhouse gas emissions and bolster energy security. INL's applied science and real-world assessments of improved energy systems and natural resource development help secure the country's future and protect the environment.

This year's LDRD projects offer a snapshot of the diverse creativity and expertise residing at INL. They offer innovative approaches to scientific questions and technical problems. In short, these projects help the laboratory maintain scientific and technical vitality, while fostering creativity and stimulating exploration at the forefront of science and technology. Most critically, they represent our dedication to the future of the laboratory, both the physical capability and the talented staff that step up to answer the nation's most pressing energy challenges.

I am proud of the accomplishments and opportunities that INL's LDRD projects provide to the nation. I encourage you to take the time to review these project narratives and reflect on their contributions.

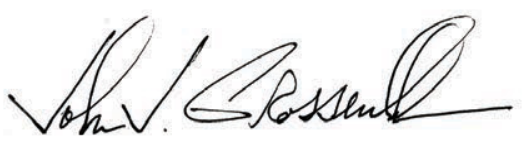


On the cover LDRD funded the development of INL's MOOSE simulation framework by a team including Jason Miller, right. MOOSE runs numerous applications including MARMOT, which models microstructural changes in nuclear fuel during fission. Developers Derek Gaston and Michael Tonks are shown in the background. More on pp. 5-8.

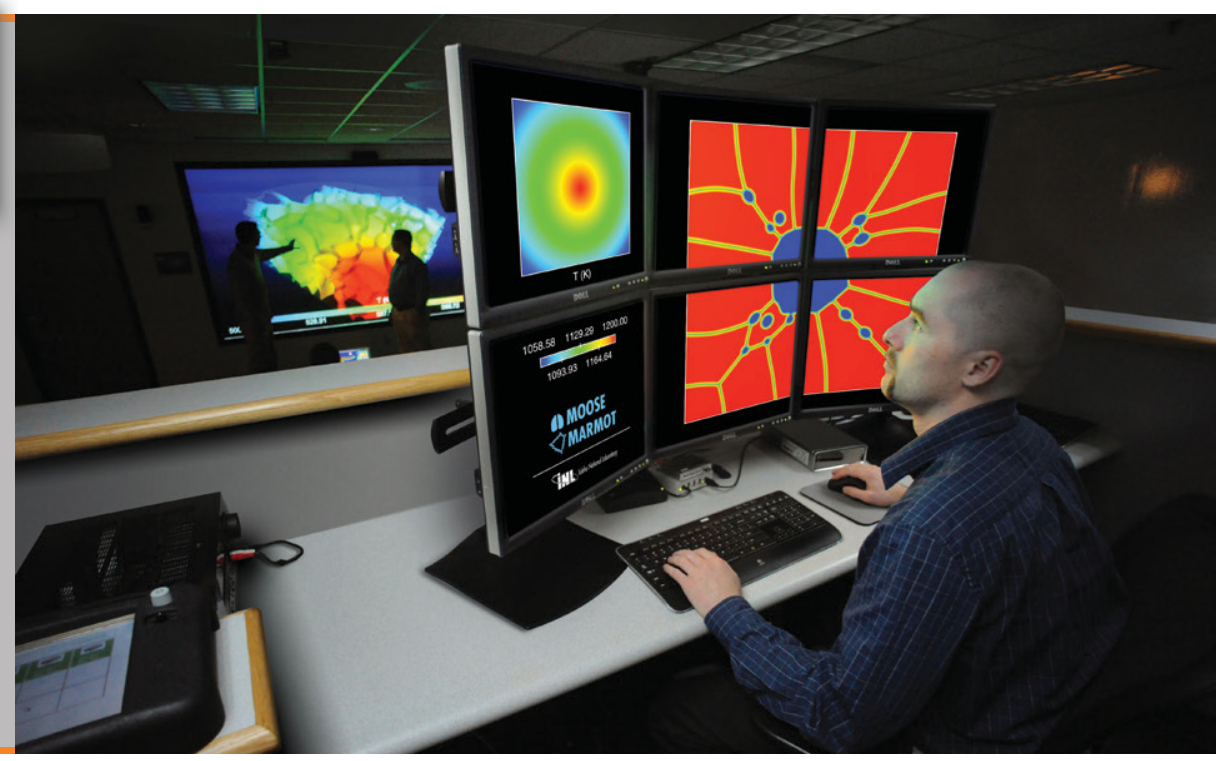

\section{TABLE OF CONTENTS}

Prepared by Idaho National Laboratory, Idaho Falls, Idaho 83415.

Managed by Battelle Energy Alliance, LLC for the U.S. Department of Energy under contract DE-AC07-05ID14517.
Editor: Nicole Stricker

Graphic designers:

Kristine Burnham,

\section{David Combs}

Photographer: Chris Morgan

\section{Introduction:}

Mission and metrics of INL's LDRD program $\ldots \ldots \ldots \ldots \ldots \ldots \ldots \ldots$

\section{Research Project Highlights:}

Brief descriptions of LDRD projects spanning the breadth of INL's research and development objectives

\section{Awards \& Recognition:}

LDRD researchers honored in FY 2012 18

\section{University Collaborations:}

Overview of LDRD university interactions including collaborations, doctoral research projects, interns and post-doctoral fellows . 24

\section{Project summaries:}

Detailed descriptions of all FY 2012 LDRD projects, including those referenced by project number in this publication.........

This report was prepared as an account of work sponsored by an agency of the United States Government. Neither the United States Government nor any agency thereof, makes any warranty, express or implied, or assumes any legal liability or responsibility for the accuracy, completeness, or usefulness of any information, apparatus, product, or process disclosed, or represents that its use would not infringe privately owned rights. Reference herein to any specific commercial product, process, or service by trade name, trademark, manufacturer, or otherwise does not necessarily constitute or imply its endorsement, recommendation or favoring by the United States Government or any agency thereof. The views and opinions of authors expressed herein do not necessarily state or reflect those of the United States Government or any agency thereof. 


\section{INTRODUCTION}

\section{INTRODUCTION}

The FY 2012 LDRD Annual Report Snapshot provides a glimpse of the diverse research performed to develop and ensure that INL's technical capabilities support current and future DOE and National Nuclear Security Administration [NNSA] missions and national research priorities.

LDRD is essential; providing a means to maintain scientific and technical vitality by funding highly innovative, high-risk, potentially high-value research and development [R\&D]. INL's diverse LDRD portfolio explores scientific and engineering concepts to develop the needs of DOE's Office of Nuclear Energy [DOE-NE] - including advanced reactor modeling, nuclear waste reduction and fuel recycling. INL's LDRD research stimulates exploration at the forefront of cybersecurity, electric grid reliability and wireless technology. The forwardlooking nature of the laboratory's R\&D strengthens the DOE mission by advancing hybrid energy systems and evolving energy security needs.

The LDRD program proves its benefit each year through new programs, intellectual property, patents, copyrights, national and international awards, and publications. It also provides a means to feed the pipeline with scientists and engineers through undergraduate and graduate internships, postdoctoral assignments and internal Ph.D. candidates.

\section{BENEFITS OF LDRD}

INL consistently realizes significant benefits from the LDRD program.

The FY 2012 metrics are shown below.

\section{FY-2012 LDRD METRICS}

National/International Awards

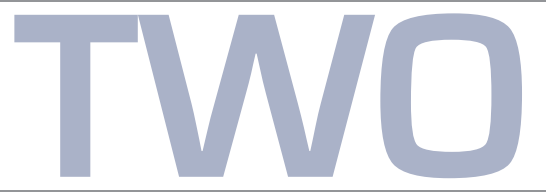

\begin{tabular}{lllllllll}
\hline Invention Disclosures & N & I & $\mathbf{N}$ & $\mathbf{E}$ & $\mathbf{T}$ & $\mathbf{E}$ & $\mathbf{E}$ & $\mathbf{N}$ \\
\hline
\end{tabular}

Patents

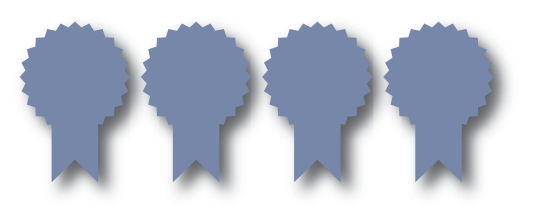

\begin{tabular}{ll|ll}
\hline Copyrights & 1 & 62 & Refereed Publications
\end{tabular}

INL Post Docs

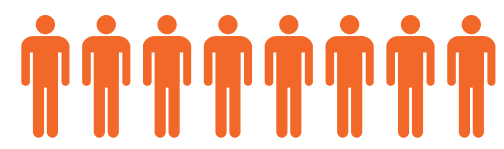

INL Students

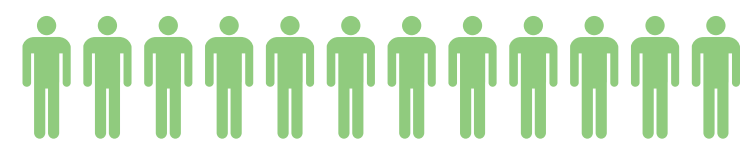

New Scientific \&

Engineering Hires

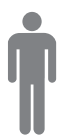

INL's LDRD portfolio explores scientific and engineering concepts to stimulate exploration at the forefront of nuclear energy, national and homeland security, and energy

security. 


\section{FY 2012 LDRD PROGRAM STATISTICS}

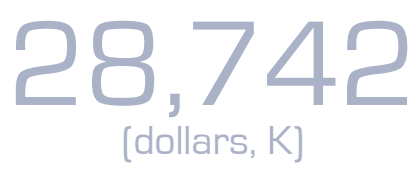

TOTAL LDRD PROGRAM COST
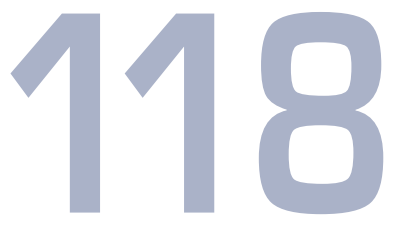

NUMBER OF PROJECTS

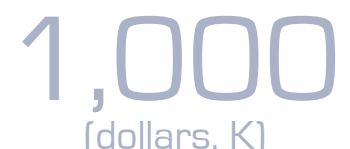

LARGEST PROJECT ALLOCATION

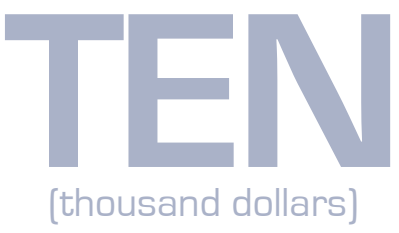

SMALLEST PROJECT ALLOCATION

\section{THE LDRD PROCESS AT INL}

INL solicits ideas for LDRD projects through an annual call for proposals. The call takes into consideration the need to support key technical capability development, collaboration with university and industry partners and other crucial research including enabling or cross-cutting science. These solicitations encourage innovative approaches proposed by individual researchers or small multidisciplinary teams.
The call for proposals includes a requirement for a pre-proposal followed by a full written proposal, a technical peer review and a management review prior to project selection. The intent of the pre-proposal process is to provide principal investigators the opportunity to briefly articulate an idea prior to investing time and effort to write a full proposal. Selected projects then submit a full detailed proposal, which is subject to technical peer review and management review. A data sheet for selected projects is then provided to DOE's Idaho Operations Office [DOE-ID] for concurrence. The continuing and proposed new LDRD projects are authorized to start work at the onset of the new fiscal year following receipt of DOE-ID's concurrence, and approval by DOE-NE of the annual LDRD Program Plan.

\section{REPORT ORGANIZATION}

This report consists of the FY 2012 Annual Report Snapshot [Part I] and individual LDRD project highlights (Part II, via CD and online at www.inl.gov/LDRD). The Snapshot begins with research highlights that exemplify the diversity of scientific and engineering research performed at INL in FY 2012, followed by sections summarizing university collaborations utilizing LDRD funding, and FY 2012 awards and recognition directly resulting from LDRD funding. Part II [CD and online] includes individual project summaries with a general description of the project, a summary of the scientific or technical progress achieved during the life of the project, a brief statement describing how the project benefited the DOE national security missions, and relevant peer-reviewed publications and presentations. The $\mathrm{CD}$ also includes appendices [acronym list, author index and project relevance to national programs] that may be useful to readers. 


\section{RESEARCH PROJECT HIGHLIGHTS}

\section{Control room modernization}

Nuclear power plants are constantly enhancing safety, but control room upgrades require a way to test and demonstrate improvements. The U.S. nuclear energy industry, the Nuclear Regulatory Commission and the DOE have an interest in assessing and improving control room operator performance. One LDRD project is developing a Human System Simulation capability at INL to support state-of-the-art studies of human responses to normal and emergency situations in control rooms and other environments where operators interact with complex technology. The reconfigurable capability enables advanced research, testing and validation using both generic and plant-specific models from industry partners [project 11-062].

Understanding the human impact on event resolution or escalation can improve nuclear energy risk and reliability margins. The existing collection of methods and practices could benefit from more scientific research. Another LDRD project is developing a scientific approach to collect human performance data at Ohio State University and INL control room simulator facilities and to model changing situations by expanding a dynamic simulation engine at the University of Maryland. A third LDRD project collaborates with the University of Idaho to establish a technical basis for the design of new nuclear power plant alarm systems [projects 12-043 and 12-086].

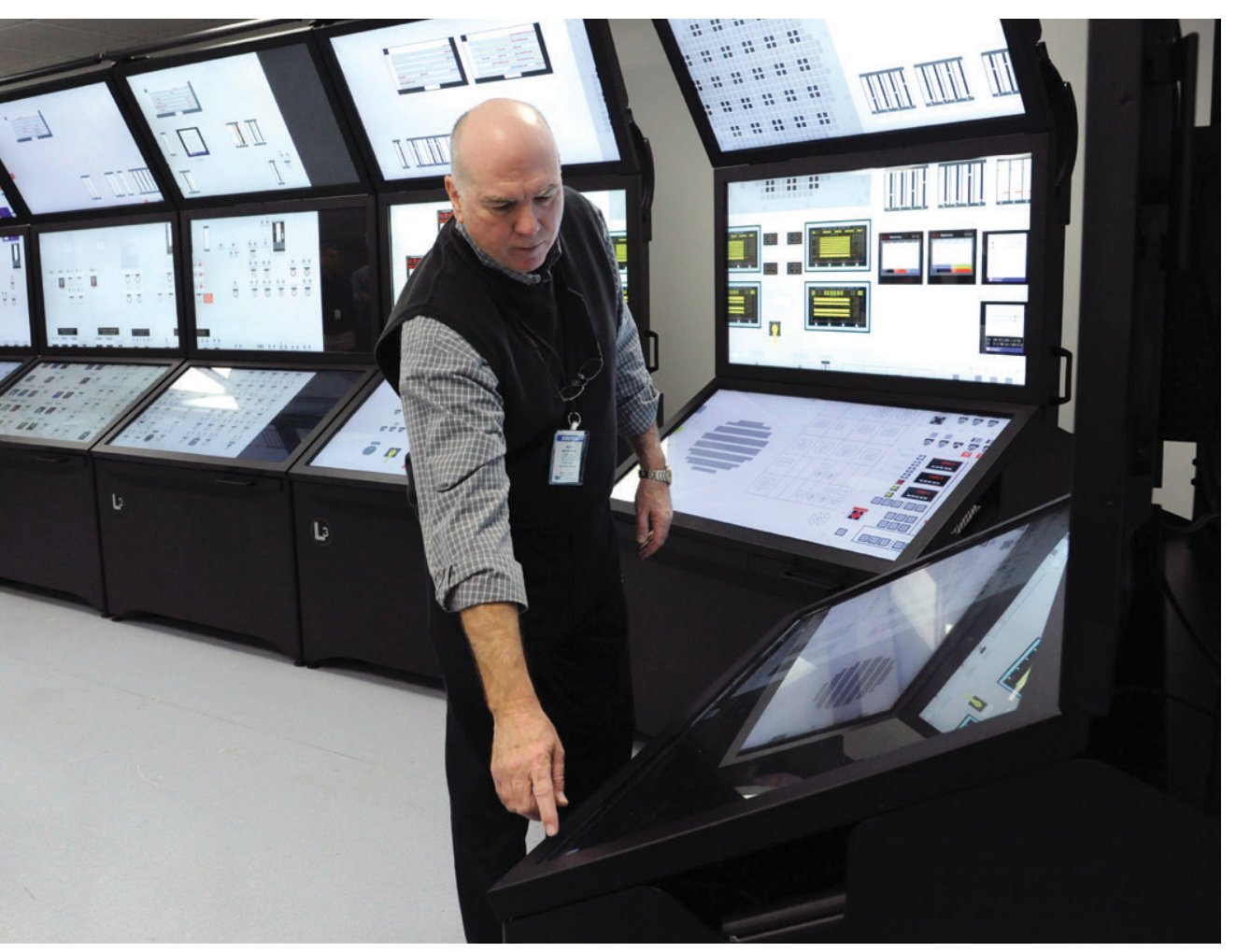

\section{Nuclear material fabrication}

Nuclear fuels could achieve higher efficiency and improved safety margins for storage if they were clad using alloys that are resistant to certain forms of materials aging. New alloys with dispersions of nanometer-scale oxide particles ["oxide dispersion strengthened" or ODS] provide enhanced resistance to creep deformation and also have been found to increase resistance to radiation damage. One LDRD project assesses the use of spark plasma sintering or field-assisted sintering as a step for simplifying ODS alloy production and potentially reducing costs. Alloy constituents have been fabricated and characterized in collaboration with Boise State University and University of Idaho [project 10-056).

Aiming to deliver a new ODS-type alloy and fabrication approach, another LDRD project eliminates timeconsuming, labor- and energy-intensive methods such as mechanical alloying. This project is developing nanoscale molybdenum/neodymia additive agents for ODS alloy fabrication. Molybdenum nanoparticle precursors have been produced in the 2-3 nanometer range. Broad application of this technology would overcome a 100-year-old science and technology barrier, would bring significant energy savings in the production of ODS alloys, and could have tremendous commercial value when applied to steels [project 12-061).

LDRD project 11-062 is developing a Human System Simulation capability for studies of human responses to normal and emergency situations in control rooms. 


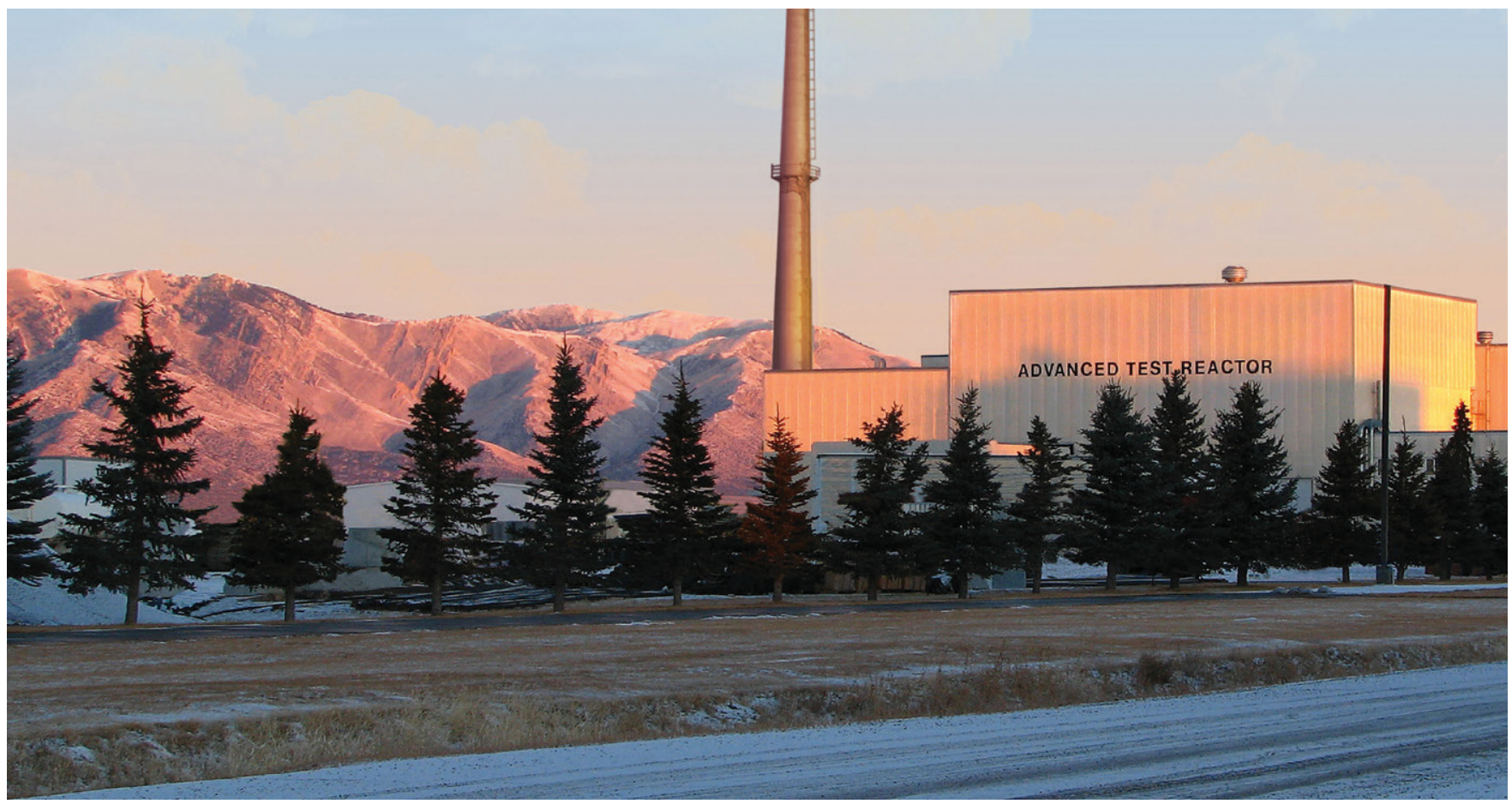

\section{Advanced reactor modeling}

INL's Advanced Test Reactor [ATR] can be used as a platform for verification and validation of advanced modeling and simulation and as a research tool to help enhance light water reactor performance. To advance this goal, an LDRD project is creating a new application, called Bighorn, for the Multiphysics Object Oriented Simulation Environment [MOOSE] framework. The physics contained in Bighorn will simulate the mass and energy transport of reactor systems coolant, which is not possible with current modeling tools. Bighorn will enable state-of-theart modeling of single- and multiphase flow, with strong coupling to solid-state heat transfer such as the thermal energy transport in nuclear fuel. This project will help advance ATR modeling and simulation to the forefront of computational methods for nuclear reactor design/analysis, which has applications including light water reactors, Next Generation Nuclear Plant concepts and sodium-cooled fast reactors [project 11-061].

\section{Success Story}

An LDRD-funded hybrid laser-gas metal-arc welding (GMAW) process aligns with DOE's Office of Nuclear Energy efforts to develop advanced reactor technologies, which will require more efficient fabrication processes. The FY 2012 project's proof-of-principle resulted in a successful proposal under the Nuclear Energy Enabling Technologies (NEET) program (project 12-116). 


\section{Next-generation test reactor}

The costs associated with maintaining current DOE test reactors and converting them to use low-enriched uranium may make it practical to consider building a single new research reactor. Addressing the design of such a reactor is a daunting task. An LDRD project is exploring the feasibility of a new test reactor that can use low-enriched uranium and meet diverse irradiation needs currently served by DOE reactors. Working with the INL experts developing low-enriched uranium fuel, a design team is exploring concepts, right, for the MATRIX (Multiple Application Thermal Reactor for Irradiation eXperiments, project 12-117].

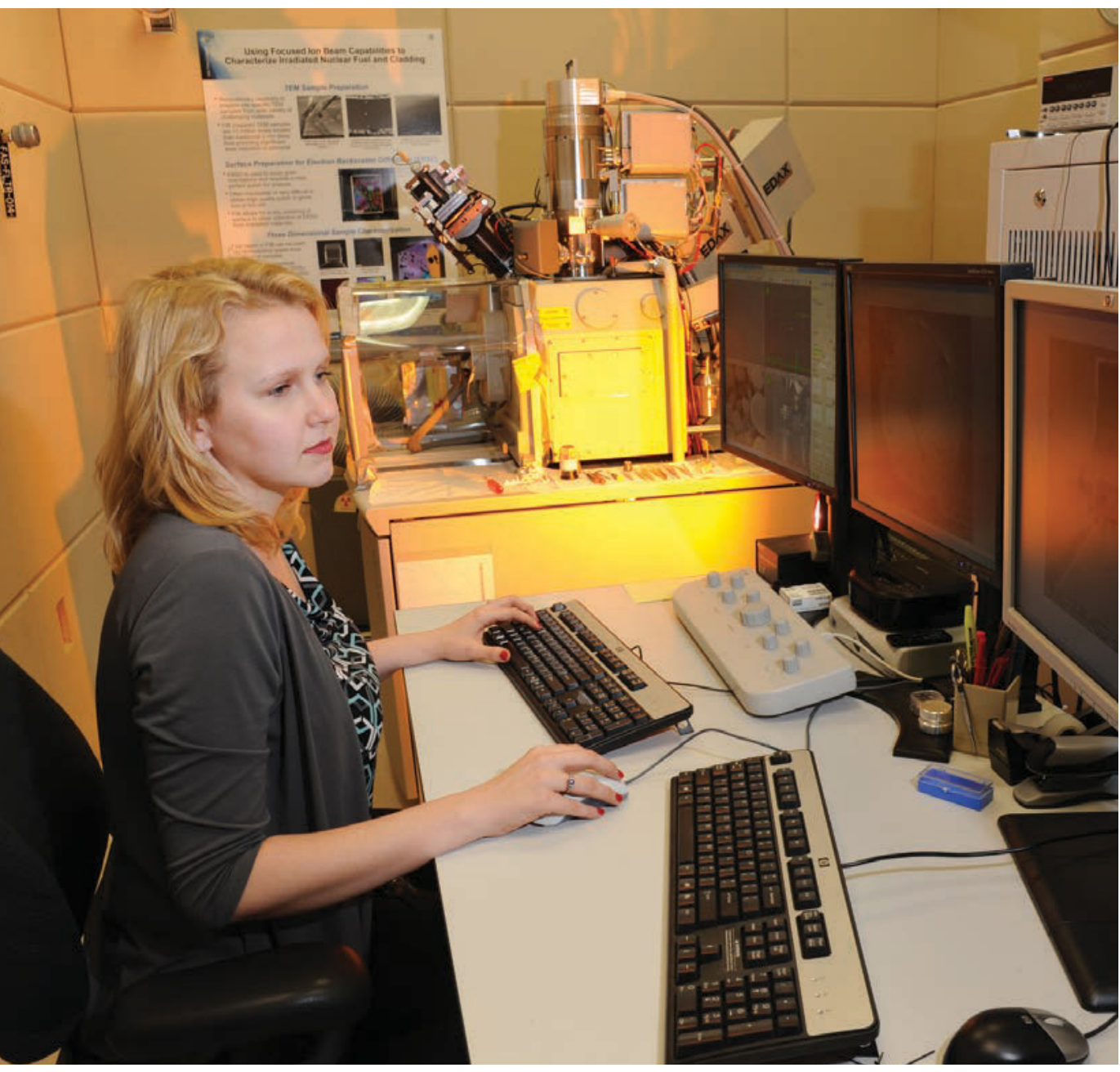

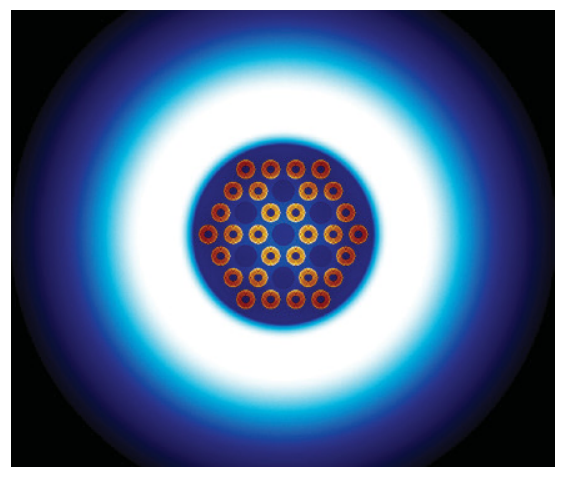

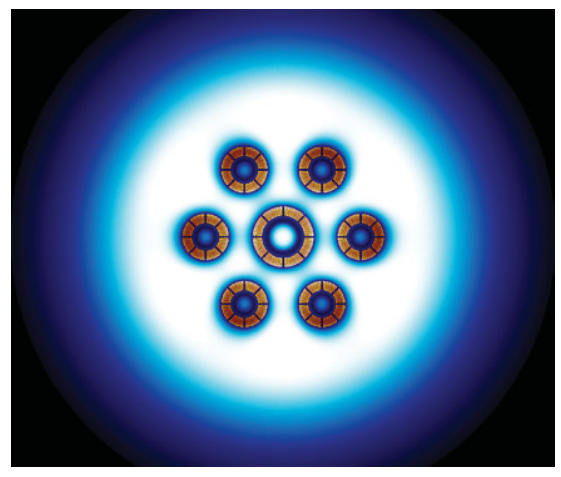

\section{Stronger nuclear materials}

The objective of this LDRD project is to understand the fundamentals of nuclear fuel performance by helping link experimental efforts and modeling. The project is developing a method to reconstruct realistic microstructures from electron back-scatter diffraction patterns of unirradiated and irradiated uranium oxide fuel and Zircaloy cladding. The reconstructions can then be used in MARMOT, an INL modeling application that simulates microscopic behavior of nuclear fuel during irradiation. Having the ability to study the crystal structure, chemistry and microstructure of irradiated fuel in three dimensions is critical to understanding the fundamentals of fuel performance [project 12-031). 


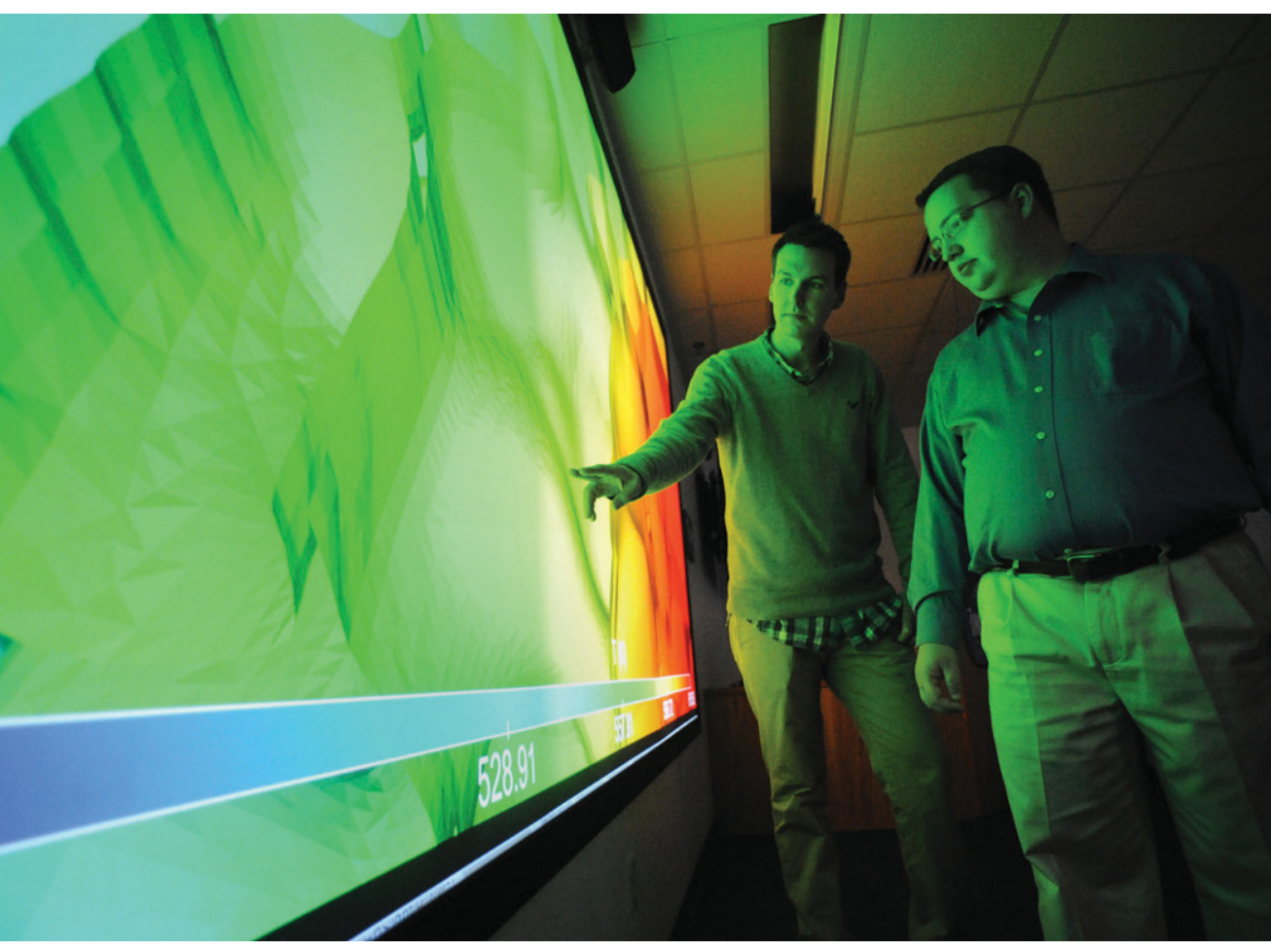

Body-centered-cubic metals are used extensively as structural materials in reactor cores. However, there is a knowledge gap regarding the underlying deformation mechanisms associated with such metals under nuclear reactor conditions. An LDRD project is building atomisticbased knowledge of deformation behavior under varying conditions. The research enables scientists and engineers to better understand and predict how irradiation and inert gases may affect structural material performance in the reactor. Such a capability will extend the lifetime of existing nuclear power plants and allow improved material designs for future plants [project 10-008].

\section{Nuclear fuel modeling}

Modeling and simulation, above, can help reduce the cost and time required to develop new nuclear fuel forms and to understand the behavior of fuel at high burnup. This LDRD project focuses on reliable uncertainty analysis of such multiscale simulations of nuclear fuel performance. The state-of-the-art capabilities developed through this LDRD project will lead to improved predictive capabilities for multiscale models of nuclear fuels [project 11-074]

Until recently, state-of-the-art computational tools simulating nuclear fuel performance prohibited analysis of important 3D behavior or application

\section{Success Story}

The MOOSE

simulation framework

has revolutionized

predictive modeling in an

array of scientific fields.

LDRD funding supported the development of several MOOSEbased applications, which now support multiple DOE research programs and are licensed for use by 25 domestic and foreign laboratories, universities and companies. 


\section{RESEARCH PROJECT HIGHLIGHTS}

to new fuel materials, new designs or extended fuel burnup. INL's MOOSE computational framework was used as the basis for INL's engineering-scale fuel performance code, BISON. For another LDRD project, the mesoscale fuels code MARMOT was developed using the MOOSE framework. The project also coupled

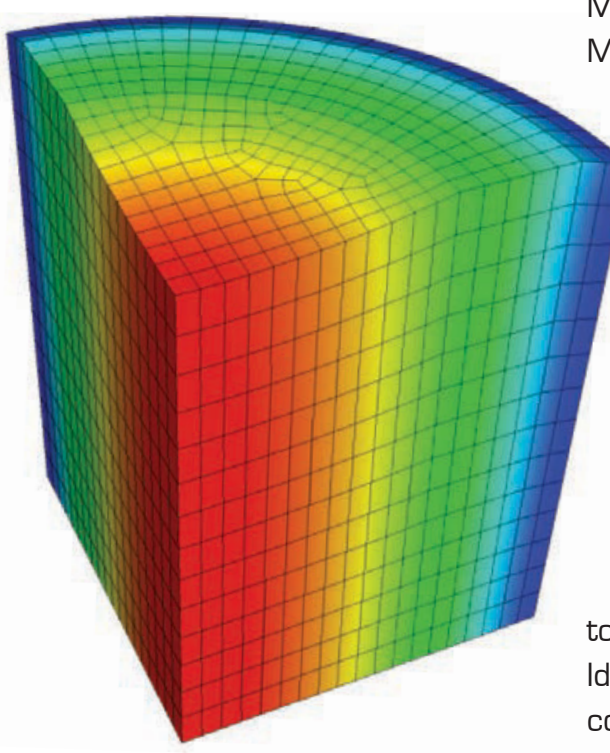

MARMOT and BISON to create a powerful multiscale, parallel, 2D and 3D fuel

simulation capability that is truly predictive. This capability was demonstrated by simulating the behavior of a highly resolved full-length discrete-pellet fuel rod. The capability also was used to study the effects of a manufacturing fuel defect known as a "Missing Pellet Surface" - the first time such behavior has been analyzed in 3D over the full life of the fuel rod [project 10-017].

\section{Nuclear waste reduction}

Pyroprocessing is a promising technology for recycling used nuclear fuel and improving the associated waste management options. The process electrochemically treats the fuel, causing fission products from the used fuel to accumulate in molten salt electrolytes. An LDRD project with University of Idaho developed methods for reusing the nonradioactive salts to produce a more concentrated radioactive waste form with less volume. By combining optimized salt freezing with optimized salt sorption by zeolites, the volume of high-level waste could be reduced by a factor of five or more compared to baseline pyroprocessing waste technology, which would vastly improve pyroprocessing's commercial viability [project 10-015).

The BISON simulation application, above, models nuclear fuel performance during fission. Crystals from a molten salt deposited on a "cold finger," right, represent a potential method for reducing nuclear waste volume.

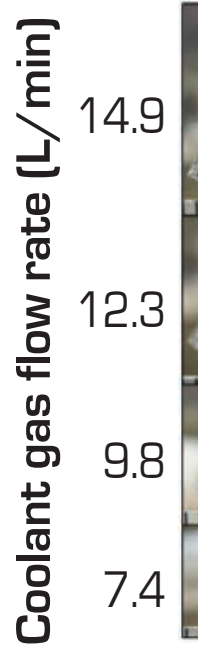

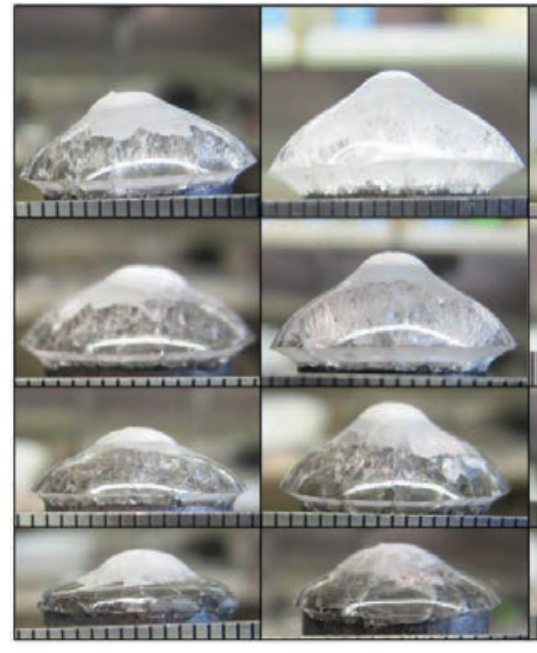

5
10

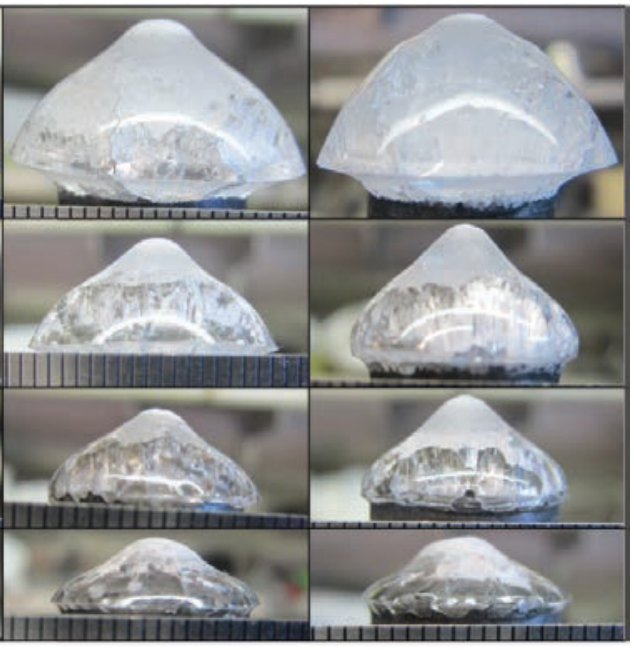

15
30

\section{Time (min]}




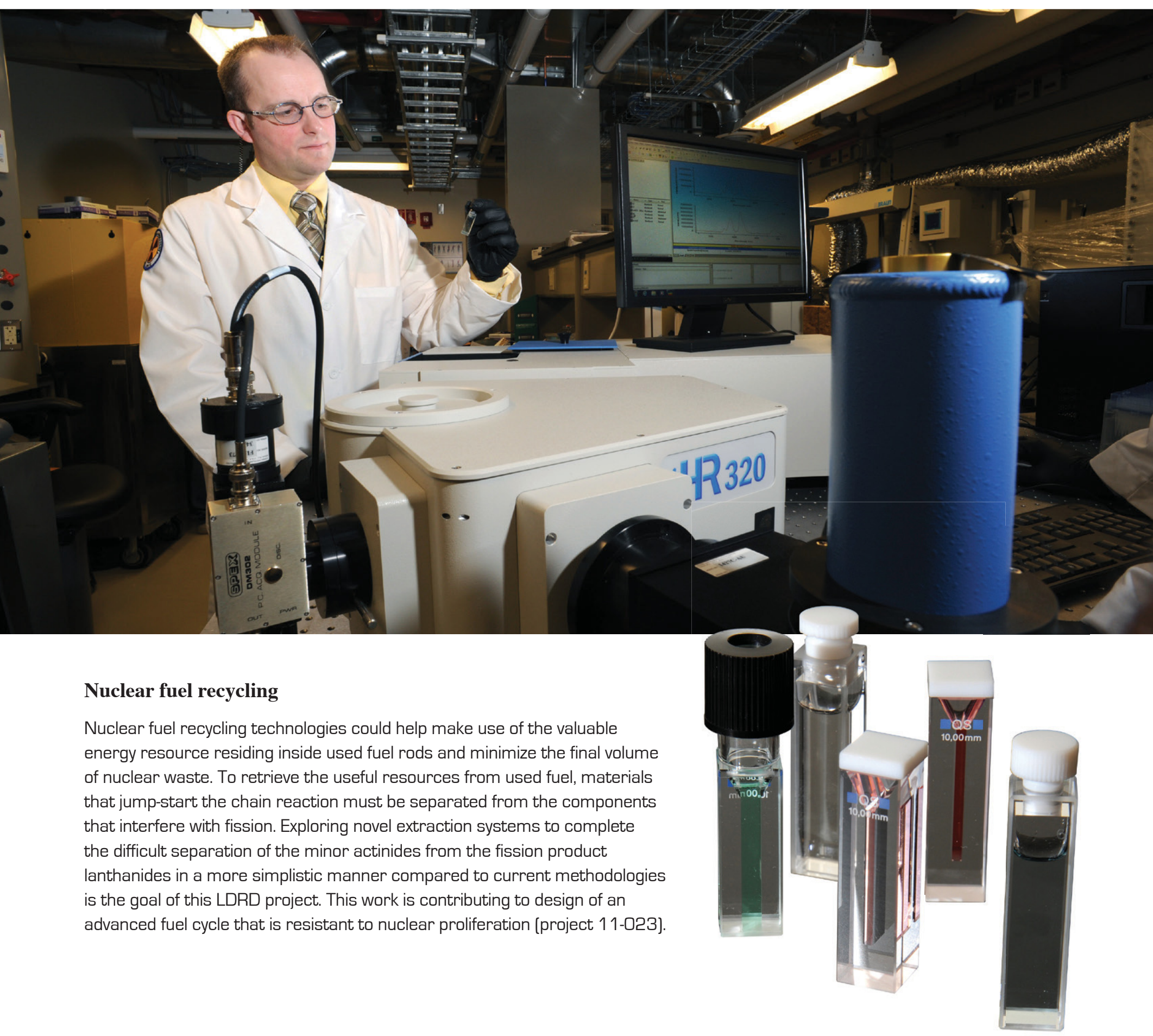




Success Story
LDRD-funded
work to improve
detection of illicit
nuclear reprocessing activities
has resulted in direct
DOE funding to continue
development and application
of laser-induced breakdown
spectroscopy (LIBS) for
complex actinide samples.

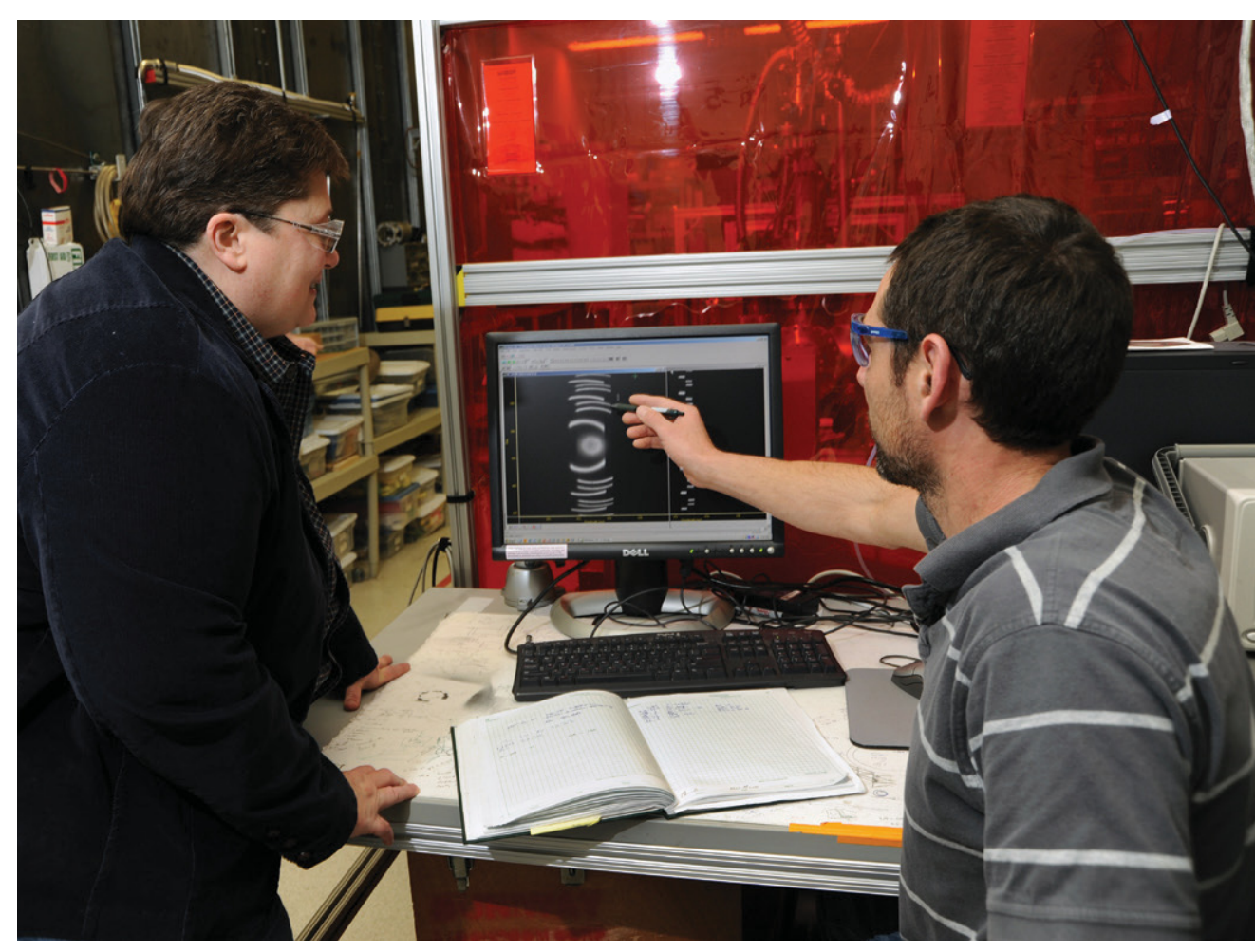

\section{Global nuclear security}

Both DOE and the National Nuclear Security Administration are working to reduce the risk of nuclear proliferation and provide technologies to improve nuclear safeguards. The detection and identification of actinides during reprocessing enhances safeguards by making material tracking less intrusive and more transparent. A laser-induced breakdown spectroscopy [LIBS] system for rapid, real-time elemental analysis of actinides in molten salts and mixtures of radioactive metals from dried solutions was developed under an LDRD. Such analyses can improve detection of illicit reprocessing activities [project 07-052, restarted in FY 2011].
A Blue Sky LDRD portfolio project would enable improved, less expensive miniaturized instruments that could be employed by International Atomic Energy Agency inspectors for detecting potential nuclear proliferation violations. The total ion control [TIC] technology is a radically simple, robust concept that significantly improves detection limits and miniaturization of analytical instruments, such as mass and ion mobility spectrometers. TIC can also facilitate field monitoring for environmental contamination, exploration for oil and mining [e.g., rare earth elements], and detection of explosives and chemical warfare agents [project 12-081]. 


\section{Advanced radiation detection}

Technical challenges currently make nuclear monitoring difficult for a number of applications including:

- inside centrifuge enrichment halls,

- in high-throughput spent nuclear fuel handling and processing facilities,

- within the high radiation fields of pyroprocessing hot cells,

- for advanced transuranic fuel forms,

- for active interrogation of cargo and

- in standoff screening systems.
An LDRD project is exploring innovative concepts for radiation detection methods to address such shortfalls. The methods are unconventional because they transcend traditional sensor reliance on neutron and gamma rays or because they seek to adapt current measurement approaches for use in new applications. Researchers studied long-length scintillating fiber bundles for radiation detection so that equipment commonly used by law enforcement and military personnel could be cost-effectively adapted for emergency radiation detection and be incorporated into a distributed sensor network for wide-area radiation field monitoring [project 11-059).
Developing a novel radiation detector concept capable of distinguishing gamma rays and neutrons while potentially providing directional information for security inspections and emergency response is the objective of another LDRD project. The project focused on high detection efficiency, radiation discrimination, source direction and miniaturization by exploiting the exceptionally high neutron capture capabilities of the naturally occurring, stable isotopes of gadolinium [project 12-092).

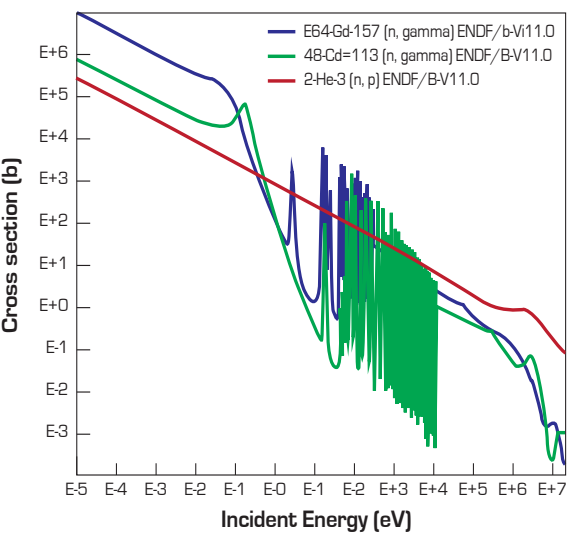

Advanced radiation detection approaches include long-length scintillating fiber bundles, left, and using gadolinium (green and blue plots above), which has exceptionally high neutron capture capabilities compared with common neutron detection materials (red plot). 


\section{Success Story}

Transforming

industrial control

systems to be threat-

resilient is the goal of INL's

Instrumentation, Controls

and Intelligent Systems

(ICIS) Distinctive Signature.

ICIS anticipates emerging

challenges associated with the nation's critical infrastructure including its utility grid and communication networks.

The multidisciplinary team of researchers and universities established in 2007 thrives on a focused research strategy of LDRD projects.

\section{Industrial and grid security}

Establishing resilient infrastructures that operate when sensors and physical assets are perturbed is an important national objective. Two related LDRD projects created state-of-the-art technology to address this goal. The first helps enable a resilient electric power grid monitoring system that is applicable to the Smart Grid, where many deployed sensors may be subject to off-normal events. The Resilient Condition Assessment Monitoring (ReCAM] System enables graceful degradation [as opposed to collapse] under natural or malicious sensor malfunctioning. The second project, the Resilient Monitoring, Adaptation, and Control [ReMAC] System, emphasizes control strategies by extending and integrating the ReCAM achievements and monitoring technologies developed by Purdue University. Specifically, ReMAC develops companion methods for addressing controllability and stability challenges of these systems [projects 10-037, 12-082].

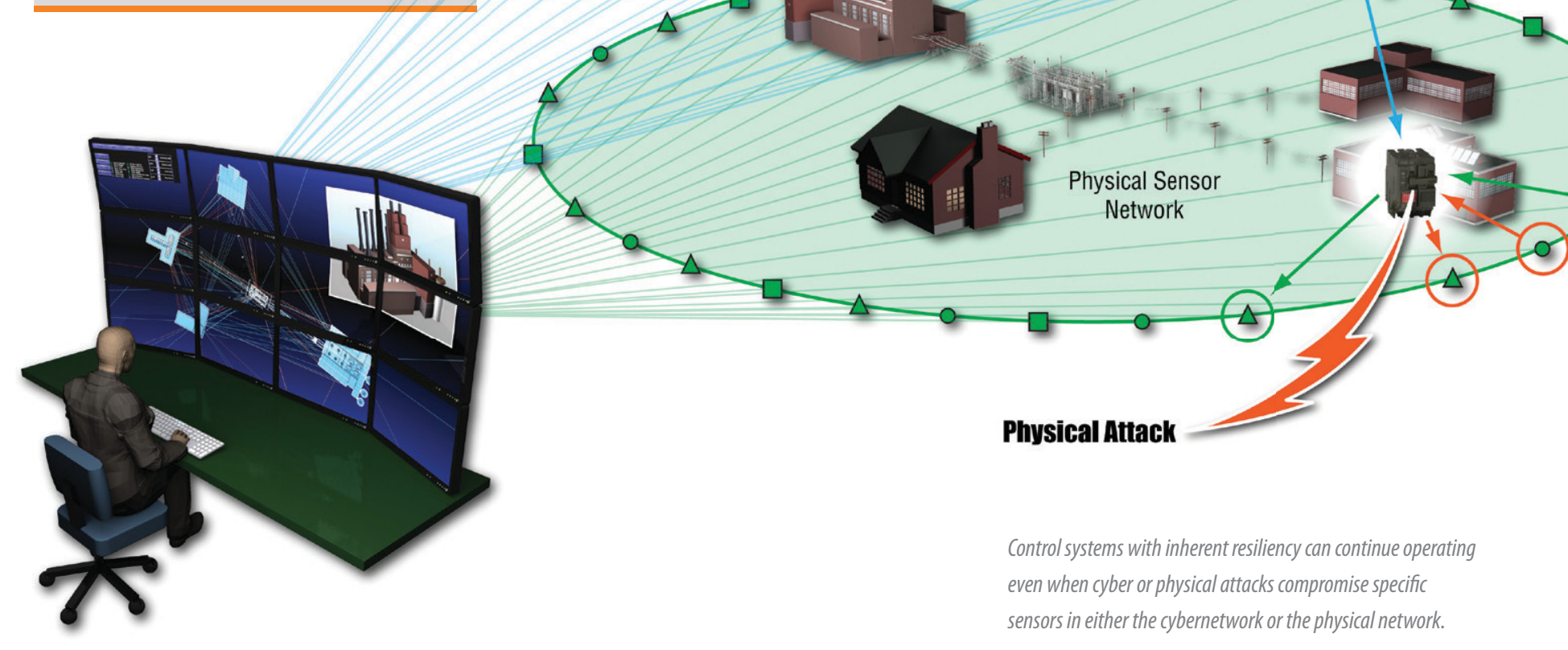




\section{“ICIS has uniquely}

defined resilience for

control systems and

infrastructure, which

has now become a

nationally critical

$R \& D$ priority."

- Tamer Başar, University

of Illinois professor and

chairman of the ICIS

external advisory

review board

\section{Cybersecurity}

Previous cybersecurity evaluations and designs were often dependent upon personal experience and limited empirical evidence. An LDRD project focused on cybersecurity vulnerability prediction, discovery and mitigation is establishing foundational science and an experimental basis in these areas, which are notably absent in many current evaluations and technologies. Researchers studied the misclassification of software bugs as "not vulnerabilities," and demonstrated that the number of misclassified bugs was significant. The project also furthered development of an automated bug classifier to help software development and maintenance teams more accurately identify those bugs likely to be vulnerabilities [project 11-042].

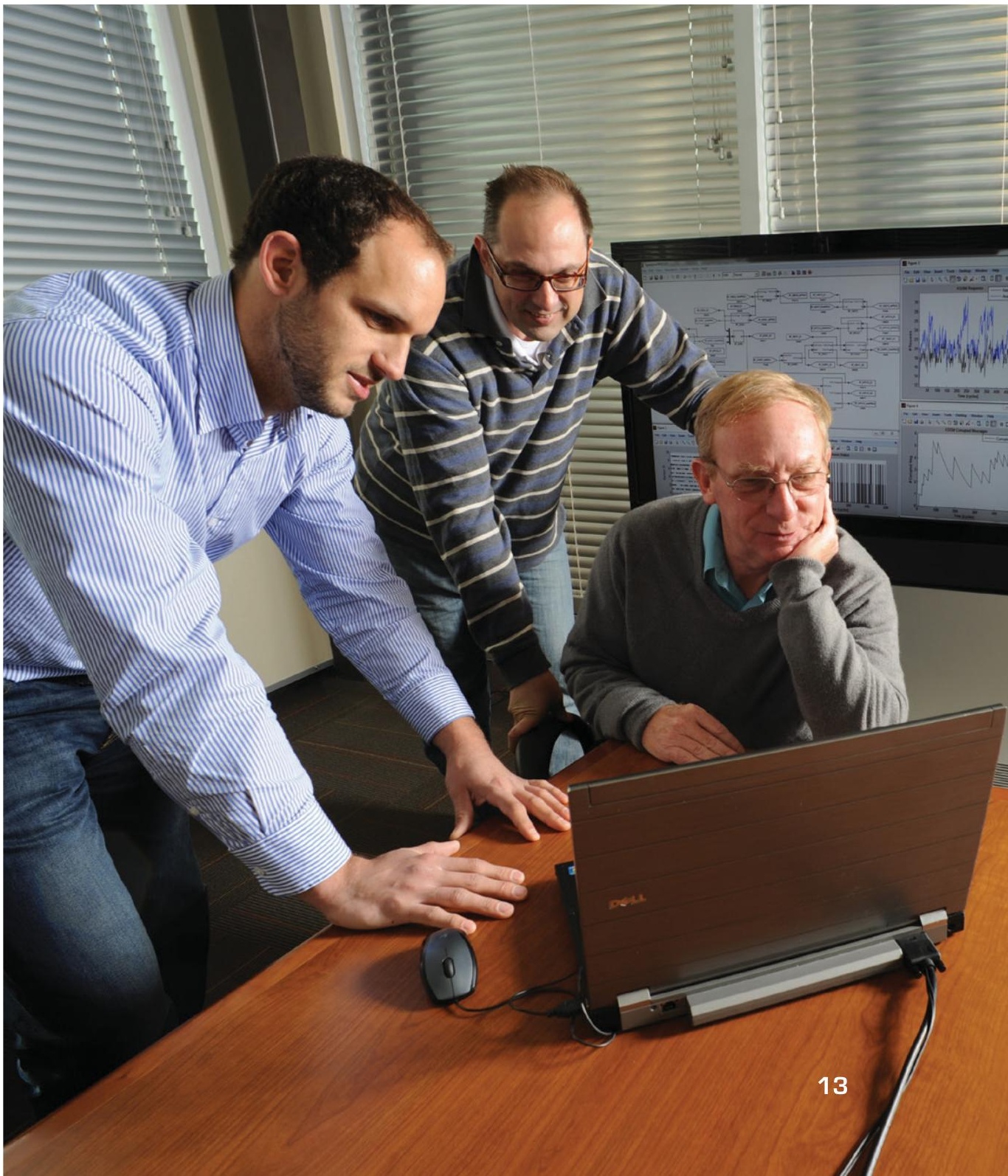




\section{RESEARCH PROJECT HIGHLIGHTS}

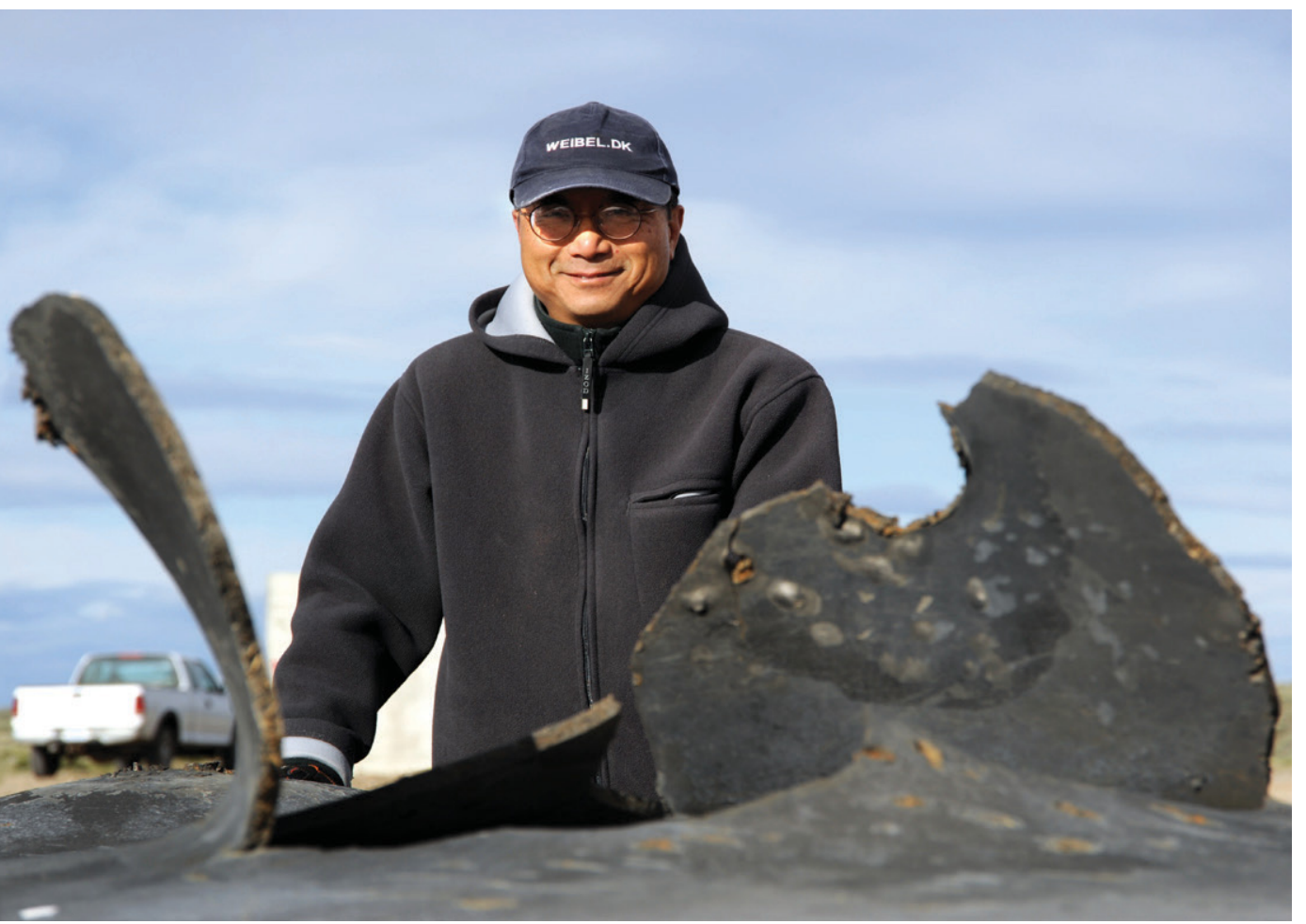

\section{Stronger armor materials}

Advanced armor materials for military and security vehicles must be hard, lightweight and robust. Although advanced ceramics offer sufficient hardness at a fraction of the weight of steels, most are brittle and cannot withstand multiple impacts. An LDRD project focuses on four material technologies that could solve these challenges: Bainitic Alternate Armor Steel, ferroelectric [FE] crystal for defeat of shaped-charge devices, dual hardness titanium and spark plasma sintering of silicon carbide. Researchers aim to prove technological feasibility by evaluating and characterizing material properties along with new synthesis and preparation methods that will be deployable as full-scale production processes (project 11-060).

Comparison testing of a variety of armor materials revealed that FE crystals (T-X and T-Z) offer better depth-of-penetration (DOP) protection.

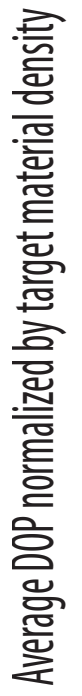




\section{Wireless spectrum optimization}

With a predicted 300-MHz spectrum deficit for mobile wireless broadband by 2014, the national need for efficient radio spectrum use has never been more urgent. This LDRD project analyzes the architectural effects and benefits of using TV white spaces in cellular networks. Results were published in the prestigious 2012 International Symposium on New Frontiers in Dynamic Spectrum Access Networks (DySPAN], and patent application 13286434 was filed for the Spectrum Accountability framework. These results will be useful for the cellular standards committees and the Federal Communications Commission for standardization and regulations, respectively [project 11-078].

\section{Success Story}

Another LDRD-

funded wireless

communication

technology now is directly

funded by the U.S. Drug

Enforcement Agency. Wireless

Spectrum Communications

(WSComm) has earned several innovation awards. Read more on pg. 23.

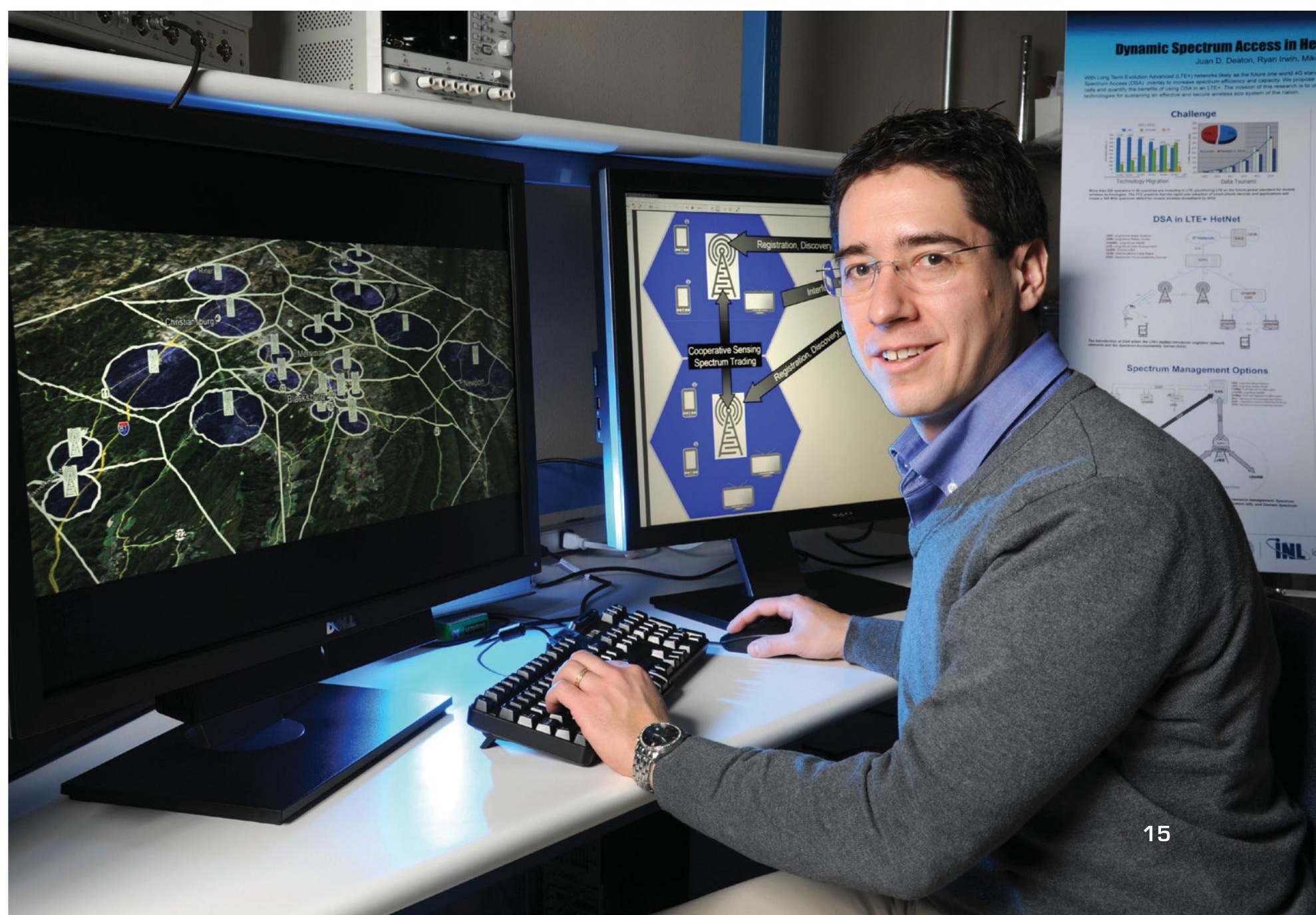




\section{Renewable power integration}

As the nation strives to achieve long-term energy security, electric utilities are incorporating increasing amounts of intermittent and distributed renewable electric power in the form of wind and solar generation. However, power generated by these sources can be highly variable and unpredictable - it has random components in the hourly, daily and seasonal time scales. An LDRD project created the Model for Electric Grid Strategies [MEGS], which can simulate how new technologies may impact grid stability. MEGS uses a hybrid modeling technique to simulate both the effects of complex load management strategies over multiple time scales and the contribution of individual consumer behavior to the power grid's operational needs [project 10-073].

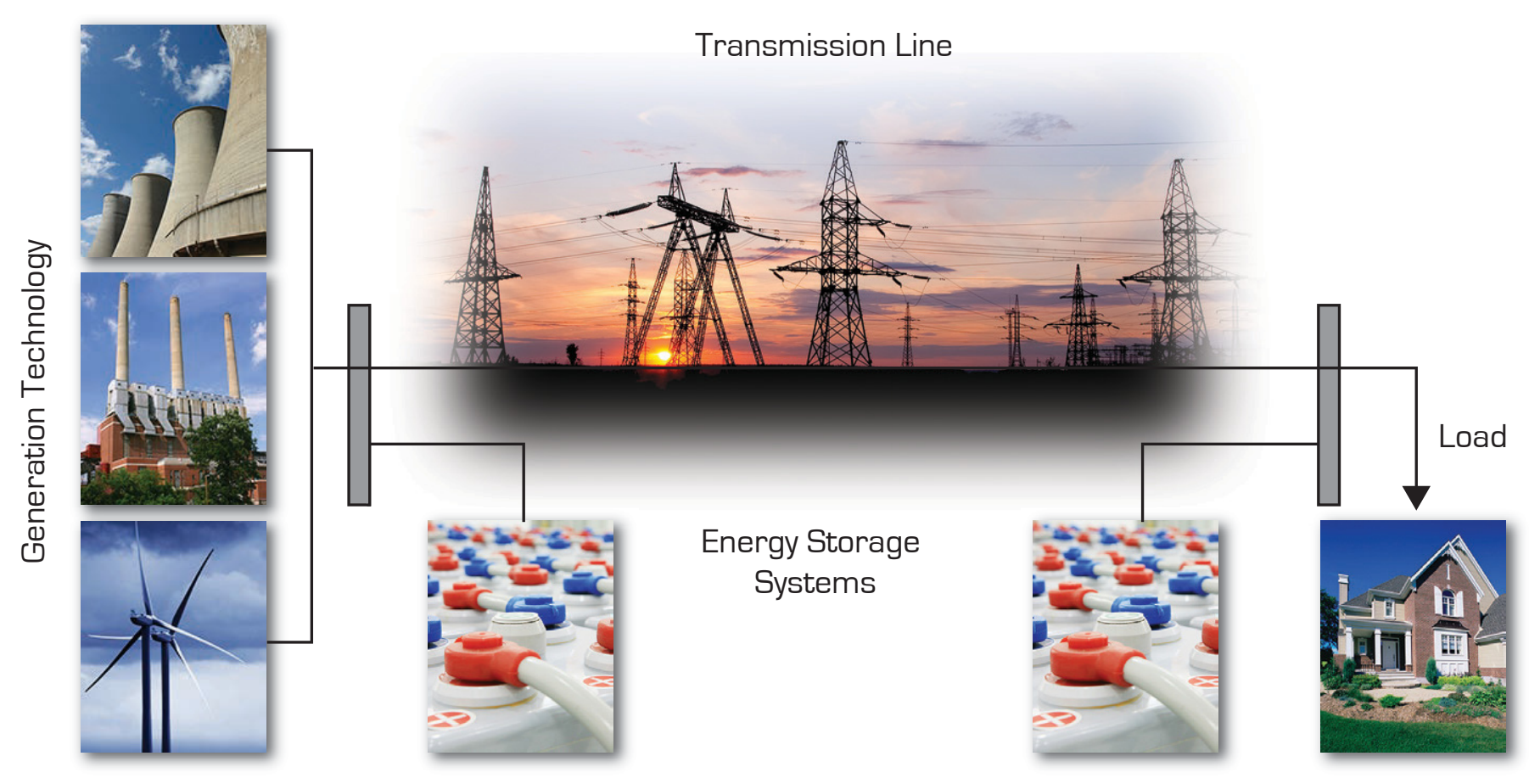

Evaluating how energy storage technologies could help integrate renewable and hybrid energy resources into the electric power grid is the goal of another LDRD project. Many storage technologies worked well at small scales and for niche applications, but energy density, power density and capital cost issues remain challenging. The project studied integration of generic variable generation into a simplified grid, and introduced energy storage systems near the generation and load centers to assess energy storage costs and benefits [project 11-007]. 


\section{RESEARCH PROJECT HIGHLIGHTS}

\section{Energy and resource management}

DOE's Energy-Water Nexus program is focused on understanding the linkages between energy development and water consumption. Current energy planning approaches do not account for the interplay between energy and water development. An LDRD project devised a creative solution in the form of a simulation framework that includes the system-level feedbacks between long-term electricity planning metrics and long-term water planning metrics. The Water and Energy Systems Tool [WEST] was demonstrated in the Snake River Basin and can create immersive, stakeholder-inclusive simulations to address questions about long-term energy-water management strategies. These simulations can be shared to create a forum for energy and water system management that better incorporates human response to drivers of change [project 10-065).

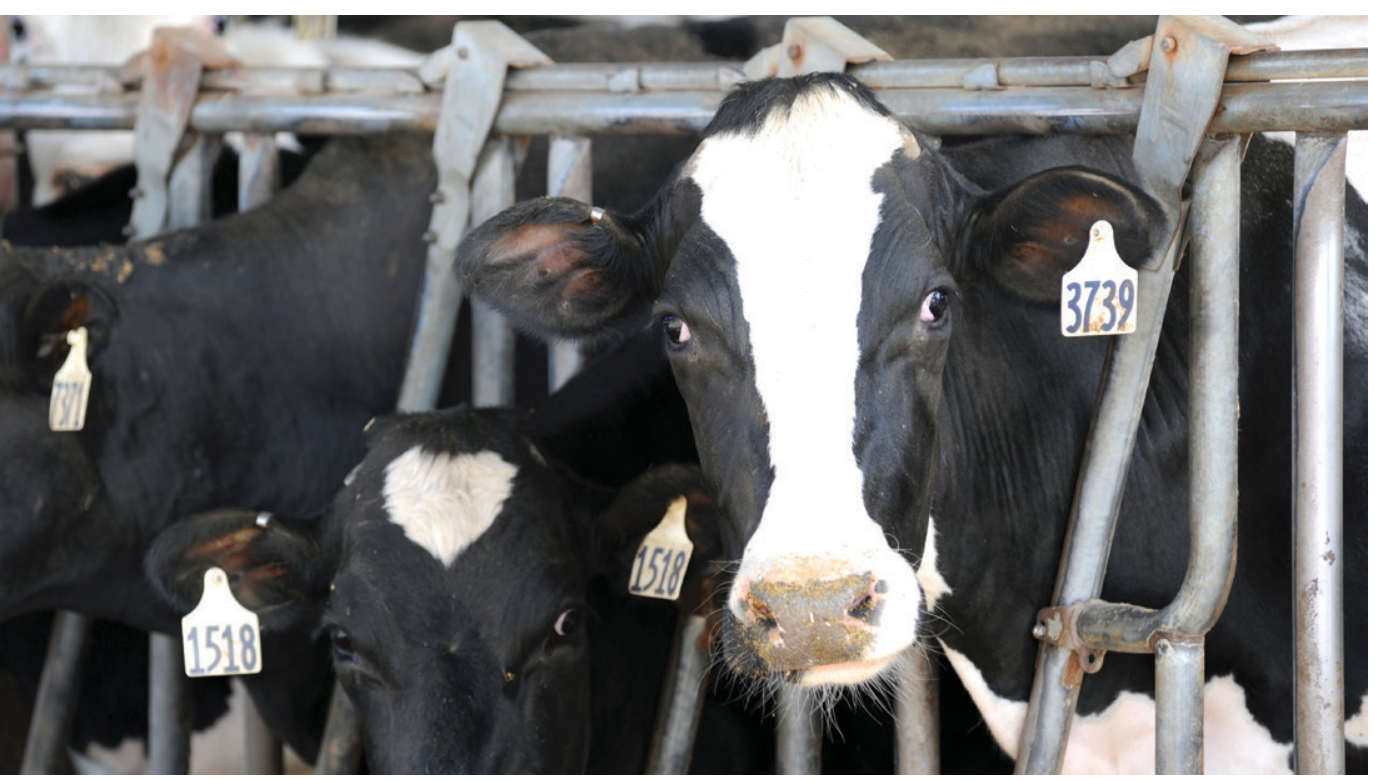

Focusing on maximum resource recovery from manure could simultaneously produce multiple high-value commodities while addressing environmental concerns.

\section{Dairy bioenergy}

Valuable energy products can be made from dairy manure. However, current manure management strategies don't fully recover valuable organic matter and are ineffective in handling greenhouse gas [GHG] emissions or removing nutrients. Focusing on maximum resource recovery from manure could simultaneously produce multiple highvalue commodities while addressing environmental concerns. An LDRD project supported by more than a dozen off-campus university students studied two novel processes for optimizing conversion of Idaho dairy manure into energy products. The first process maximized conversion to methane, while the second sequestered anaerobic digestion emissions to produce lipid-rich algae that can be converted to biofuels. A life cycle analysis of the system revealed significant $\mathrm{GHG}$ reduction (project 10-080). 


\section{Fossil fuel synthesis}

The ability to convert significant quantities of carbon dioxide $\left[\mathrm{CO}_{2}\right]$ directly to fuels is limited because $\mathrm{CO}_{2}$ itself inhibits kinetics, necessitating development of new catalysts. A catalyst developed and characterized in an LDRD project drives fuel creation from domestic products such as biomass, waste, natural gas and coal. Research efforts also discovered that hydrocarbons in the jet fuel molecular weight range were the predominant product [project 11-031].

hydrogen - to synthetic fuels.

The work has led to an invention

disclosure record and

Cooperative Research and

Development Agreement.

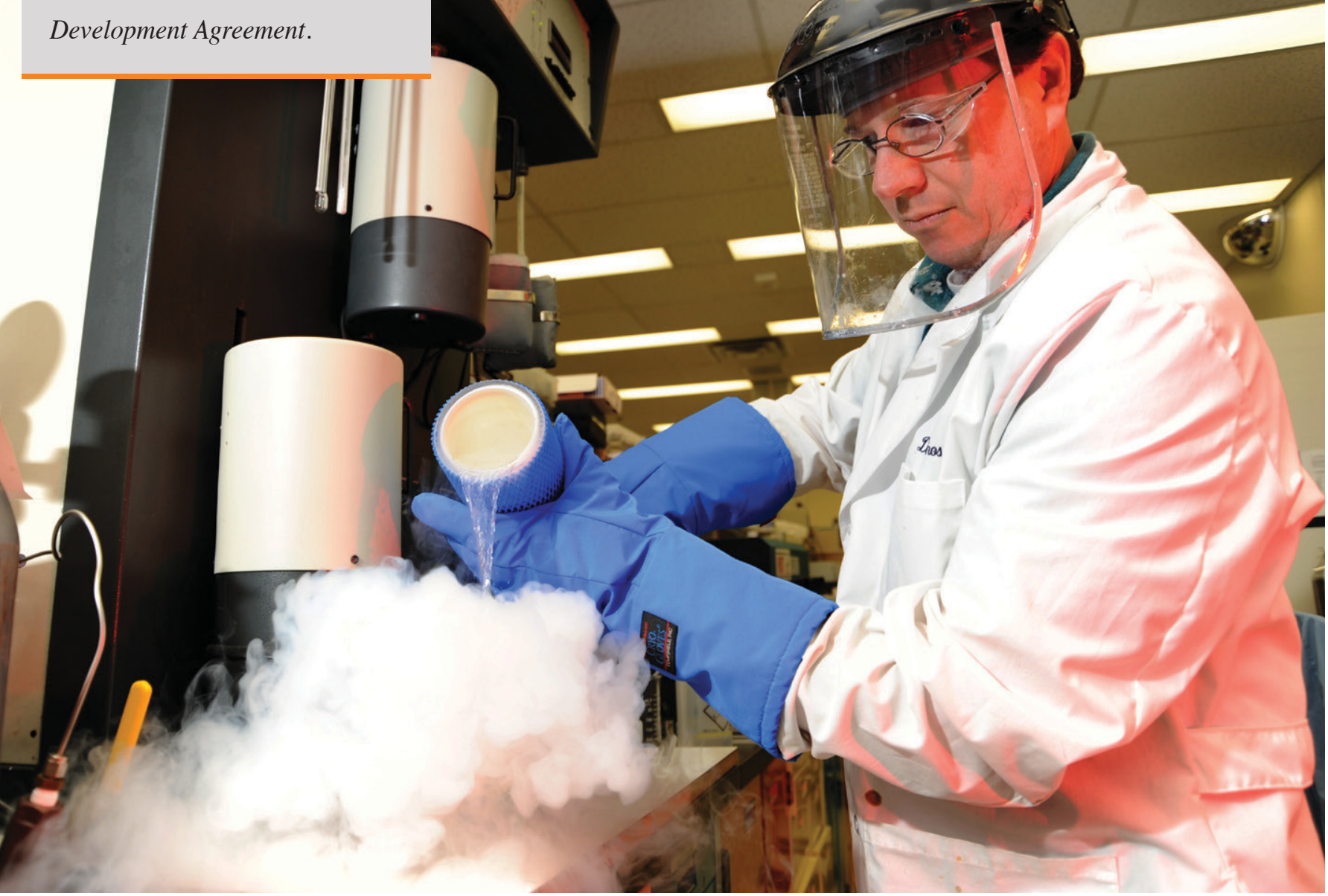




\section{Sustainable fracking}

As industry taps unconventional energy resources, DOE can help identify and mitigate risks of new extraction approaches. For example, recovery of the vast unconventional fossil fuel resources in the Mountain West will require significant amounts of water. Extraction in the rapidly expanding Bakken Formation relies heavily on hydraulic fracturing, which raises concerns about artesian aquifers that have historically supported grazing and agriculture. An LDRD project aims to address these risks as Bakken extraction proceeds westward. It is evaluating the water needs for the eastern Montana Bakken development, characterizing groundwater resources, identifying key areas where development may be water-limited and developing an approach for optimizing water usage. Incorporating water impacts into drilling plan designs may reduce negative water impacts to manageable levels [project 12-108].

Pairie Pothole

Prairie Pot

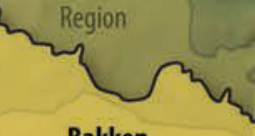

Bakken

Formation

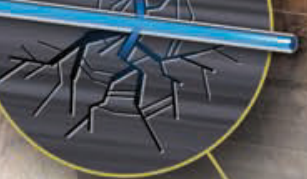

Drinking Water Aquifers

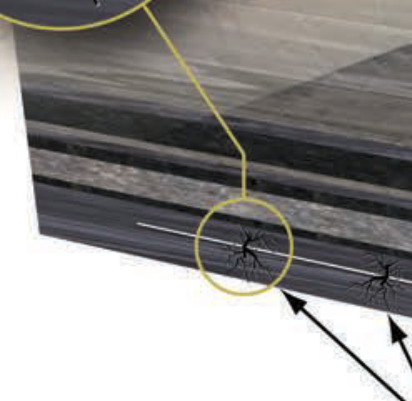

Fracture Stages 


\section{Hybrid energy systems}

Integrated energy systems could improve fossil resource utilization, reduce greenhouse gas emissions and stabilize renewable energy contributions. These hybrid systems can divert resources during periods of low electrical demand by dynamically altering their production mode to deliver power, heat or chemical products. One LDRD project is a laboratory-scale demonstration of synthetic fuel [synfuel] production relevant to hybrid systems. The test bed can synthesize liquid methanol an ultra-clean synthetic fuel and fuel feedstock. The capability provides a test bed for key principles including 1) remote conversion of electricity and carbon-based resources into synfuels, 2) technical and economic feasibility of a modular, deployable energy conversion system, and 3] remote monitoring and control using a realtime system [project 10-059].

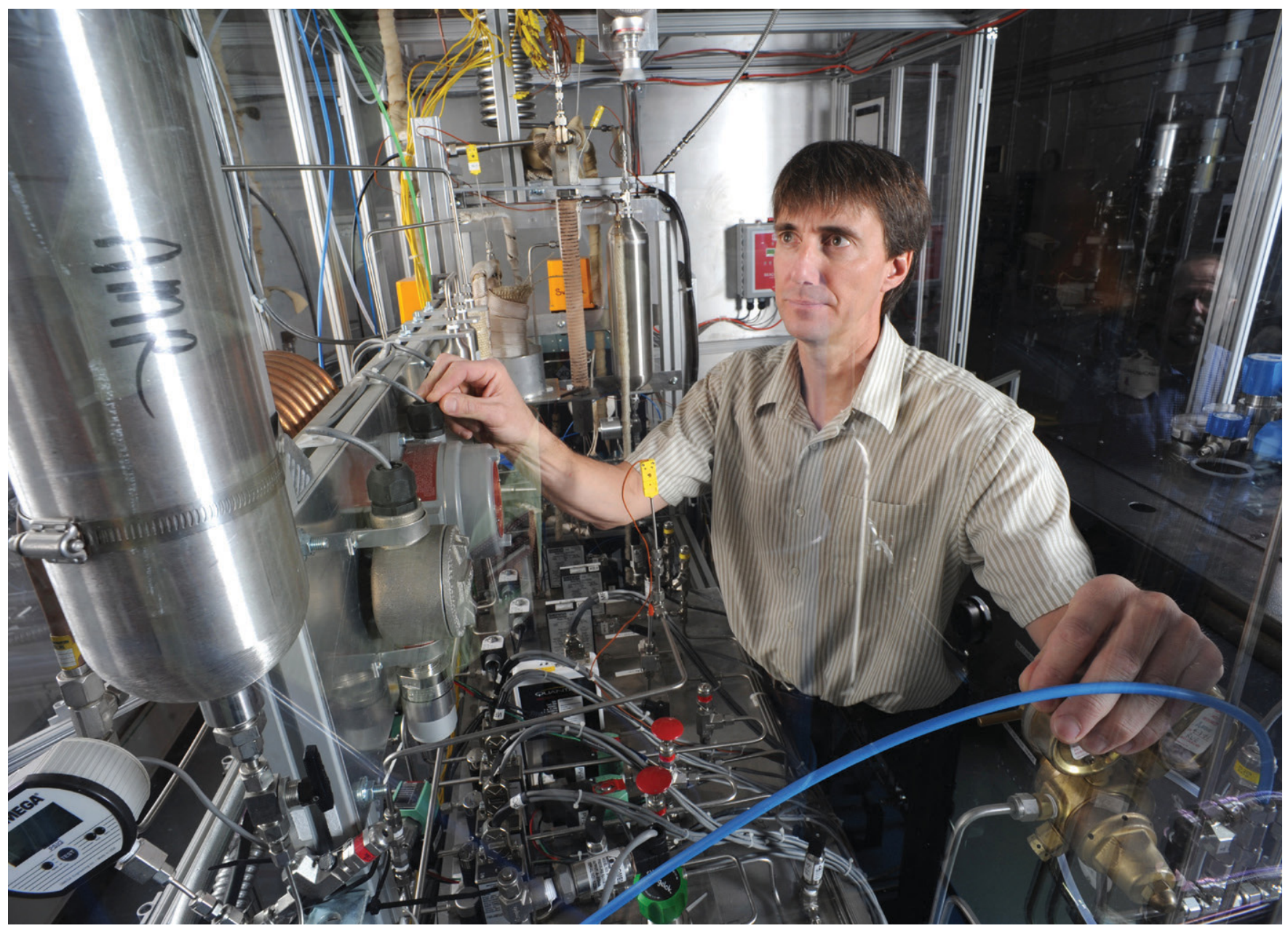




\section{AWARDS AND RECOGNITION}

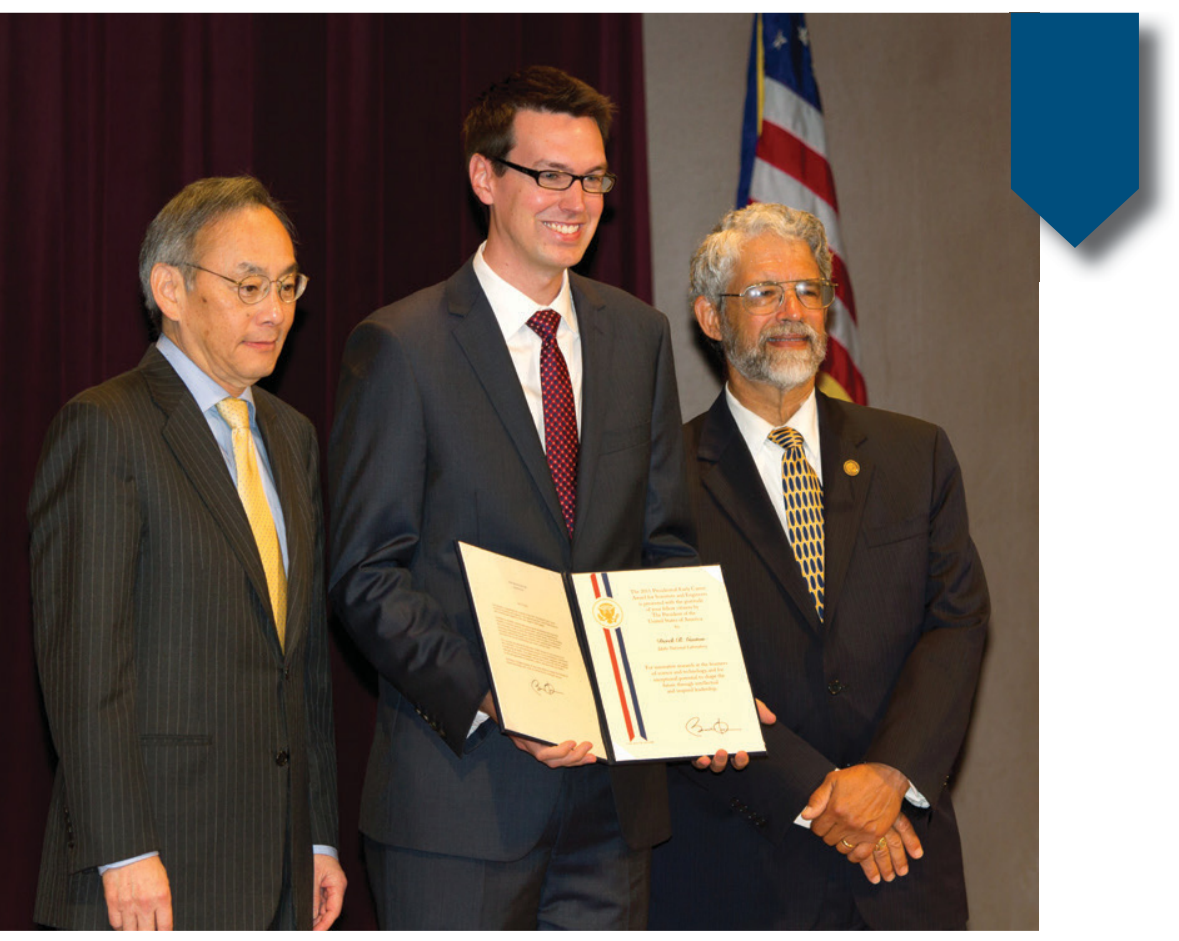

\section{DEREK GASTON}

The INL computational mathematician was one of 96 recipients of the 2012 Presidential Early Career Award for Scientists and Engineers. The award is the highest honor the U.S. government bestows on early career science and engineering professionals. As the Computational Frameworks Group lead for INL's Fuels Modeling and Simulation Department, Derek led development of the MOOSE simulation framework, which was LDRD-funded and underlies several current LDRD projects (projects 11-061 and 10-017).

"Discoveries in science and technology not only strengthen our economy, they inspire us as a people. The impressive accomplishments of today's awardees so early in their careers promise even greater advances in the years ahead." -President Barack Obama, on Presidential Early Career Achievement Awards

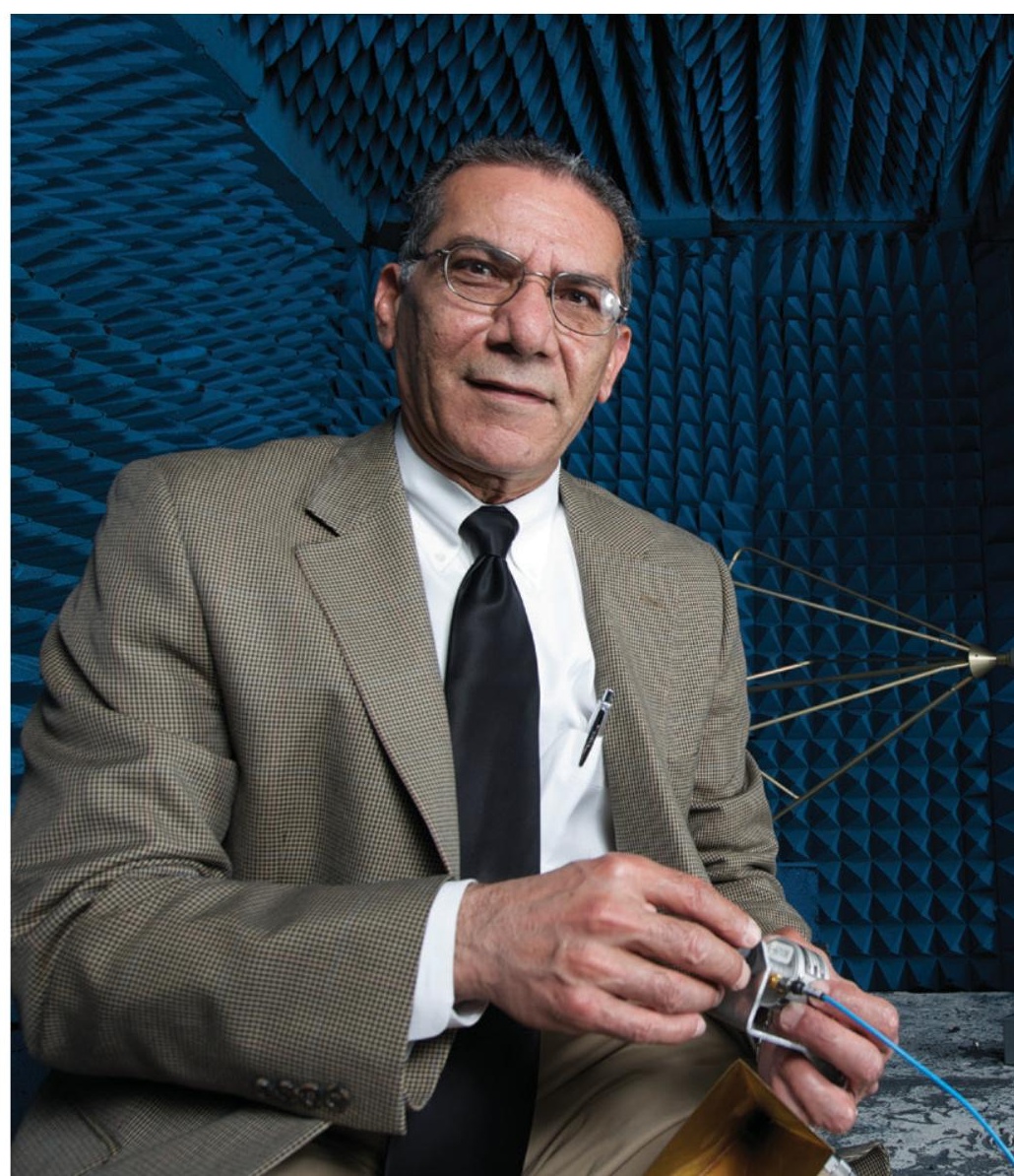




\section{UNIVERSITY COLLABORATIONS}

\section{UNIVERSITY COLLABORATIONS}

Of 118 LDRD projects funded in FY 2012, nearly two-thirds [75 projects] involve university collaborators. University collaborations foster creativity and provide opportunities for academic researchers to help find solutions to national challenges. Such collaborations also support DOE objectives for nurturing the next generation of scientists and engineers.

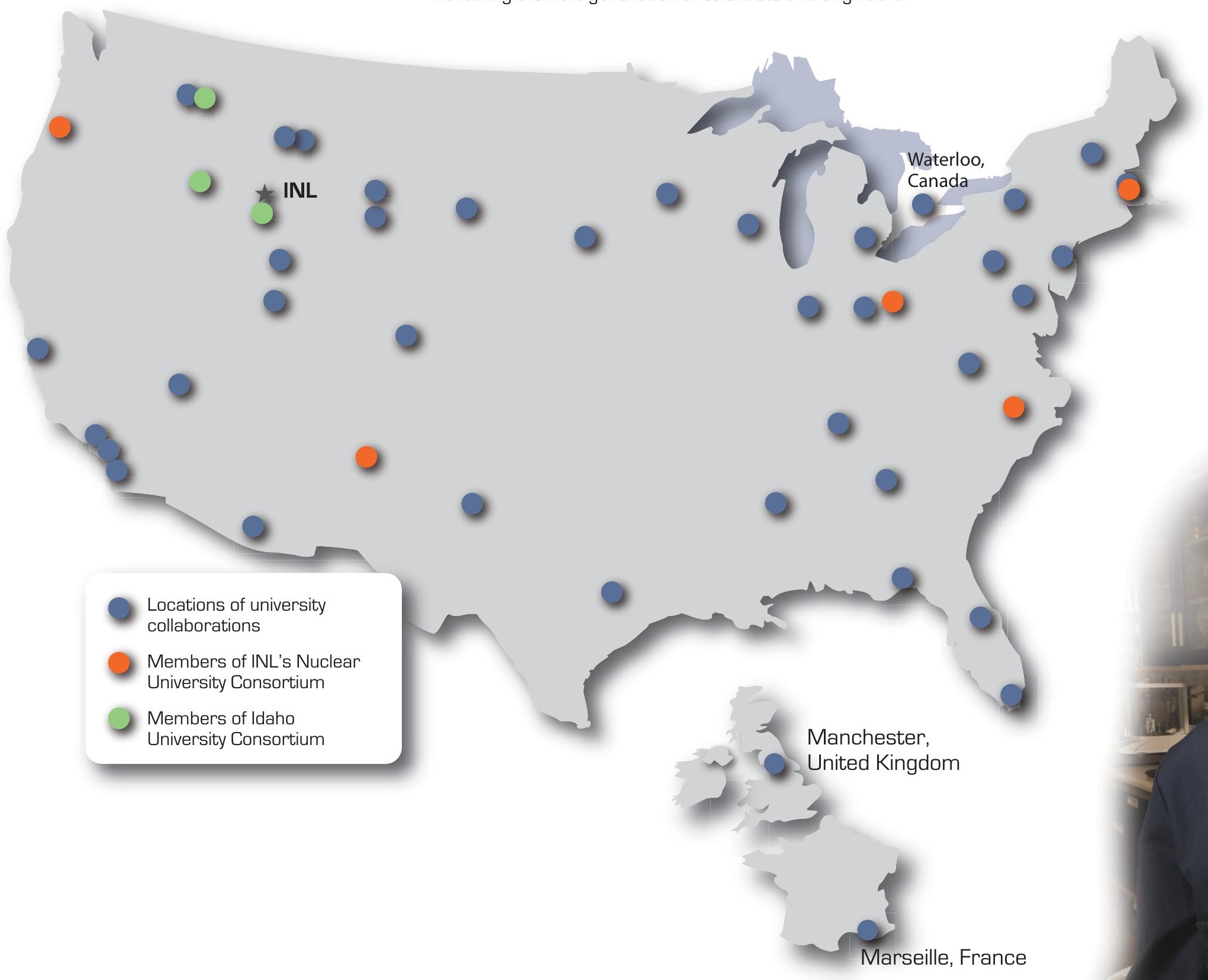




\section{SUPPORTING INL DOCTORAL RESEARCH}

Juan Deaton's doctoral research involved the LDRD project "Enabling dynamic spectrum access in Long Term Evolution [LTE] networks." It is described in the Wireless Spectrum Optimization highlight on pg. 15 [project 11-078].

Melissa Teague's doctoral research is supported by an LDRD project titled "2-D and 3-D EBSD Technique Development and Microstructure Reconstruction for Phase Field Microstructure Evolution Models." It is described in the Stronger Nuclear Materials highlight on pg. 6 [project 12-031].
The LDRD project "Speciation Behavior of Americium Oxidation States for the Separation of Americium from Curium in Nuclear Processing" is supporting Catherine Riddle's doctoral research [project 11-005].

The LDRD project "Water and Energy System Interdependency Modeling for Multicriteria Decision Analysis" is supporting Robert Jeffers' doctoral research, which is described in the Energy and Resource Management highlight on pg. 18 [project 10-065].

John Koudelka's doctoral research is supported by an LDRD project that is using high-performance computing and Web-based computational frameworks to improve soil parameter estimation and ultimately enhance runoff forecasts from hydrologic models [project 12-111].
“My LDRD project has

given me the opportunity

to distinguish myself

among my peers in

the radiochemistry

community. It is also

fostering a new distance-

learning university degree

program for INL, from

which I will be the

first graduate."

-Catherine Riddle,

$L D R D$ researcher

and Ph.D. candidate

\section{INTERNS AND POST-DOCTORAL FELLOWS}

\section{Post-doctoral fellows: \\ Interns:}

Eric Dufek

Travis Grimes

Jeremy Hatch

Narasimharao Kondamudi

Nicholas McGuire

Scott Thompson

Prabhat Tripathy

Yongfeng Zhang
Maxime Fournie

Bradley Fromm

Brandi Grover

Cynthia Hanson

Rita Hoggan

Matthew Johnson

Simon Olive

Ari Staven

Paul Talbot

Michael West

Hsingtzu Wu

Chao Xu 
The Laboratory Directed Research and Development [LDRD] program at Idaho National Laboratory advances cutting-edge research and helps develop strategic capabilities that span the lab's nuclear energy, national security and energy security mission areas.
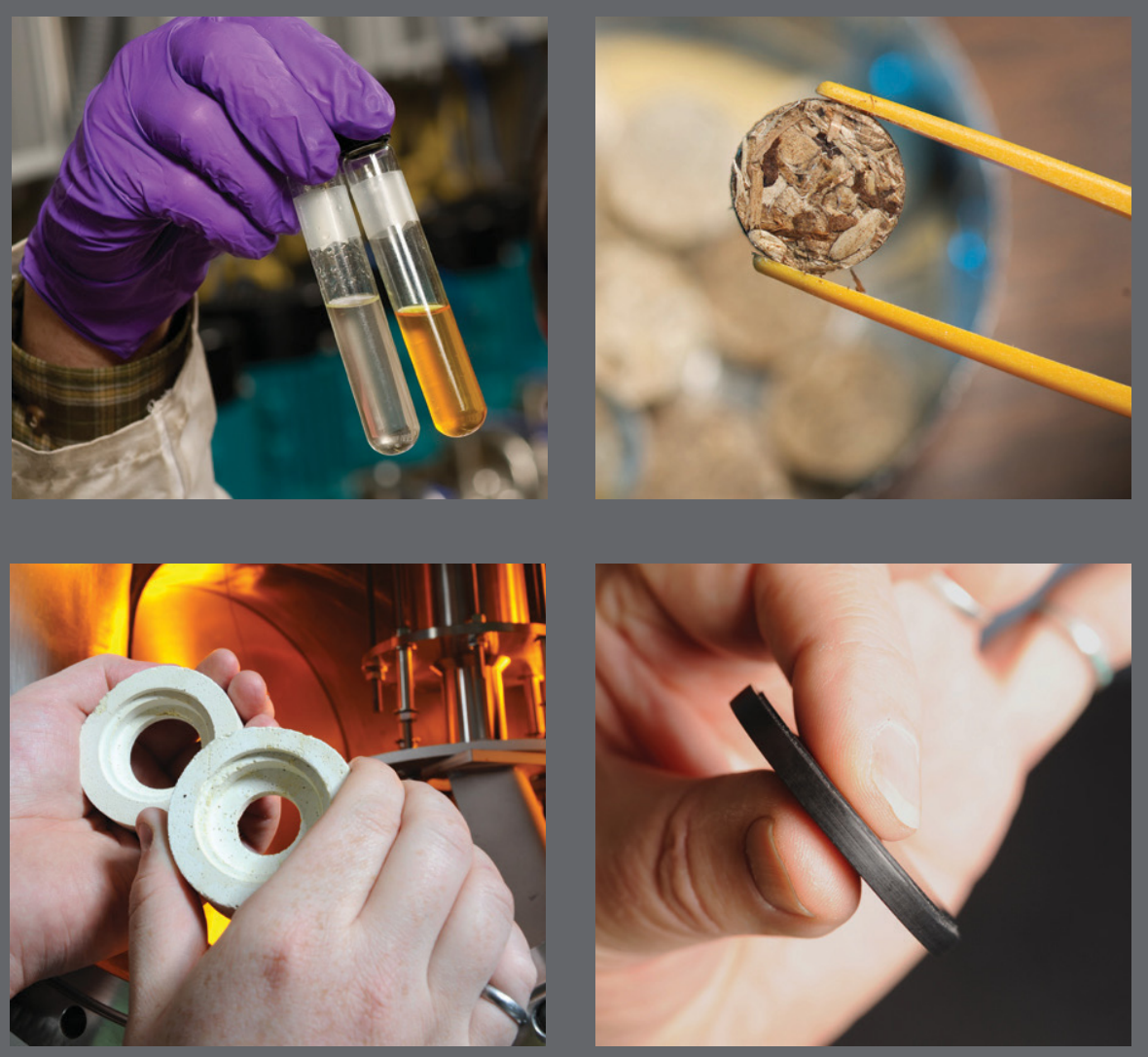

\title{
WWW.INL.GOV/LDRD
}

\author{
More information: \\ Anita Gianotto \\ 208-526-0551 \\ anita.gianotto@inl.gov \\ Dena Tomchak \\ 208-526-1590 \\ dena.tomchak@inl.gov
}

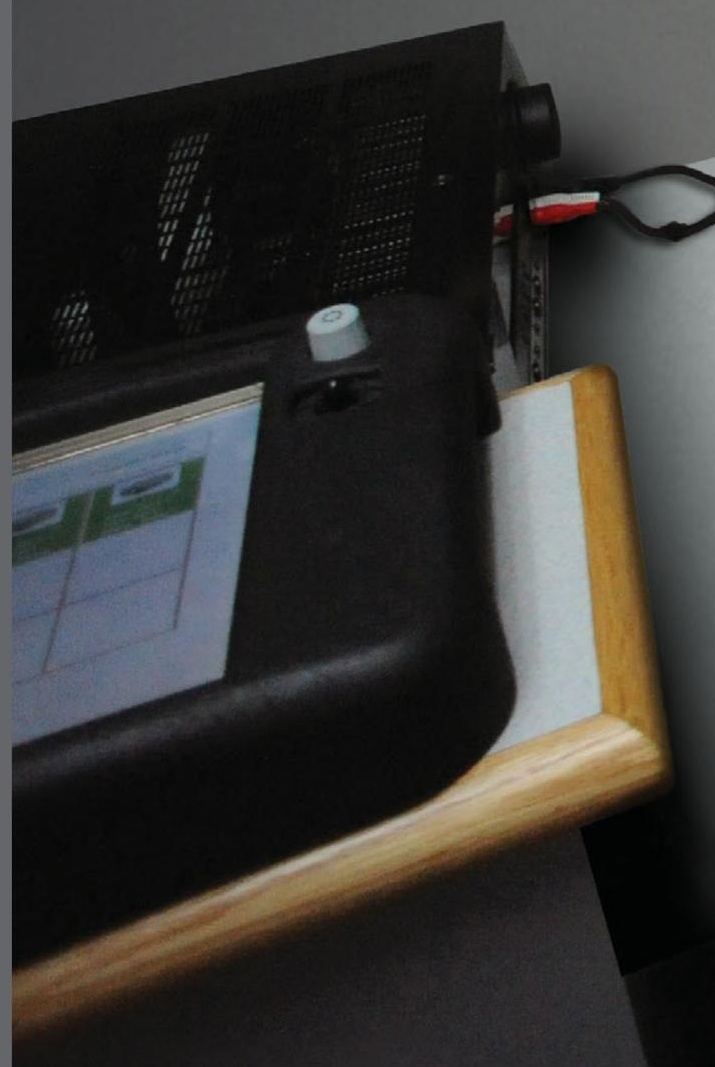

